
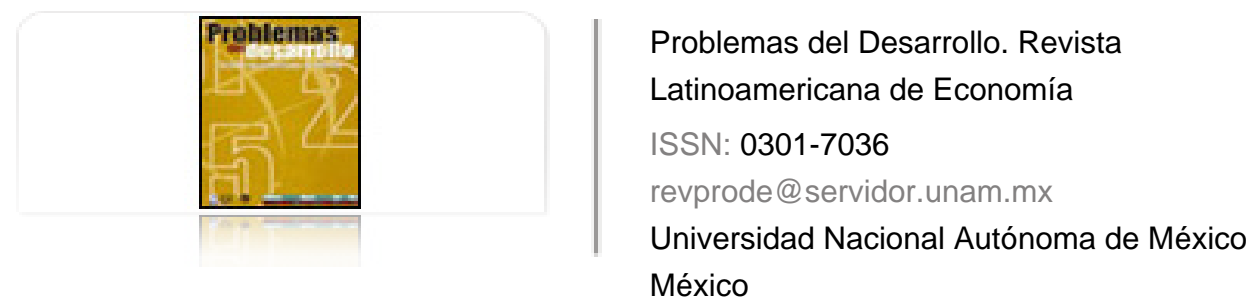

Escaith, Hubert

INDUSTRIALIZACIÓN TRUNCADA Y TERCIARIZACIÓN SUSTITUTIVA EN AMÉRICA LATINA

Problemas del Desarrollo. Revista Latinoamericana de Economía, vol. 37, núm. 147, octubre-

diciembre, 2006, pp. 45-80

Universidad Nacional Autónoma de México

Distrito Federal, México

Disponible en: http://www.redalyc.org/articulo.oa?id=11820100003

Cómo citar el artículo

- Número completo

- Más información del artículo

Página de la revista en redalyc.org

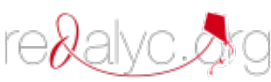

Sistema de Información Científica

Red de Revistas Científicas de América Latina, el Caribe, España y Portugal Proyecto académico sin fines de lucro, desarrollado bajo la iniciativa de acceso abierto 


\section{INDUSTRIALIZACIÓN TRUNCADA Y TERCIARIZACIÓN SUSTITUTIVA EN AMÉRICA LATINA}

\section{Hubert Escaith*}

Fecha de recepción: 5 de mayo de 2006. Fecha de aceptación: 5 de septiembre de 2006.

\section{Resumen}

El trabajo analiza la evolución de la productividad laboral en América Latina en el periodo 1960-2003. Los resultados se comparan con los obtenidos en una selección de países asiáticos. A diferencia de Asia, la industria latinoamericana no ha podido asumir un papel de polo de crecimiento y la esperada transición productiva hacia la industrialización quedó truncada. La insuficiente oferta de puestos de trabajo de alta productividad ha redundado en un deterioro de los empleos creados en los sectores de servicios, desembocando en una creciente informalidad laboral, un aumento de la desigualdad y una pérdida de competitividad sistémica. Se propone una revisión del modelo conceptual inicial para incorporar estos nuevos hechos estilizados y especificar las restricciones macroeconómicas que impidieron una completa transición hacia la industrialización y favorecieron el surgimiento de un nuevo dualismo económico y social.

Palabras clave: América Latina, economía del desarrollo, medición de la productividad, industrialización y servicios, sectores formal e informal.

* Director de la División de Estadística y Proyecciones Económicas de la CEPAL. Las opiniones expresadas pueden no coincidir con las de la organización. El autor dedica este artículo a André Hofman y agradece los comentarios de Salvador Marconi, Jürgen Weller y de tres árbitros anónimos. Correo electrónico: hpe2@yahoo.com 


\section{HUBERT ESCAITH}

Abstract

The paper analyzes the evolution of labor productivity in Latin America in the period 1960-2003. The results are compared with those obtained in a selection of Asian countries. Unlike Asia, Latin American industry has not been able to assume a role at the growth pole and the expected productive transition towards industrialization has been truncated. An insufficient supply of high-productivity jobs has resulted in a deterioration of jobs created in the service sector, culminating in growing labor informality, greater inequality and a systemic loss of competitiveness. A review of the initial conceptual model is proposed to incorporate these newly stylized facts and to specify the macroeconomic restrictions that have impeded a full transition towards industrialization, favoring the emergence of a new economic and social dualism.

Key words: Latin America, development economics, productivity measurement, industrialization and services, formal and informal sectors.

\section{Résumé}

Ce travail est une analyse de l'évolution de la productivité du travail en Amérique latine entre 1960 et 2003. Les résultats sont comparés avec ceux obtenus dans certains pays asiatiques. À la différence de l'industrie de ces pays, celle de l'Amérique latine n'a pas pu devenir un pôle de croissance et le passage à l'industrialisation escompté n'a pas été achevé. L'offre insuffisante de postes de travail de haute productivité a eu des répercussions négatives sur la création d'emplois dans le secteur des services, entraînant un accroissement de l'économie informelle et de l'inégalité sociale joints à une perte de compétitivité endémique du système productif. Cette analyse amène la proposition de réviser le modèle conceptuel initial, en incorporant ces faits nouveaux et en distinguant les facteurs macro-économiques qui ont empêché un passage complet à l'industrialisation et favorisé l'apparition d'un nouveau dualisme économique et social.

Mots-clefs: Amérique latine, économie du développement, mesure de la productivité, industrialisation et services, secteurs formel et informel.

\section{Resumo}

Analisa a evolução da produtividade do trabalho na América Latina no periodo 19602003. Os resultados se comparam com os obtidos numa seleção de países asiáticos. Em contraste com a Ásia, a indústria latino-americana não conseguiu ainda assumir um papel de pólo de crescimento e a esperada transição produtiva para a fase da industrialização ficou truncada. A insuficiente oferta de postos de trabalho de alta produtividade tem redundado num deterioro dos empregos criados nos setores de serviços, desembocando numa crescente informalidade do trabalho, um aumento da desigualdade e uma perda de competitividade sistêmica. Propõe-se uma revisão do modelo conceitual inicial para incorporar estes novos fatos estilizados e especificar as restrições macroeconômicas que impediram uma completa transição para a fase da industrialização e favoreceram o surgimento de um novo dualismo econômico e social.

Palavras chave: América Latina, economia do desenvolvimento, medição da produtividade, industrialização e serviços, setores formal e informal.

\section{Desarrollo}




\section{Introducción}

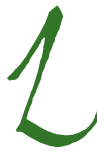

a teoría moderna del desarrollo económico — de inicio de los años cincuenta - puso mucho énfasis en la importancia de la estructura producti-

va y de su transformación en el análisis de los factores que determinan la trayectoria de transición desde sociedades tradicionales hacia economías desarrolladas, o sea industrializadas. En la misma época, las economías industrializadas de mercado exploraban las posibilidades que ofrecían las políticas de inspiración posfordista y neokeynesiana para lograr una transición exitosa hacia sociedades posindustriales de servicios.

La reunión de las dos corrientes esbozaba naturalmente la posibilidad de un continuum desarrollista, al iniciar con sociedades tradicionales de subsistencia, y transitar por una fase de creciente industrialización y diferenciación productiva y social para culminar en sociedades posindustriales basadas en una complementariedad de los sectores secundarios y terciarios. La posibilidad de un continuum, sin embargo, no implicaba la necesidad de su realización en una convergencia armoniosa, como lo subrayaban los análisis centro-periferia de Prebish.

Apoyándose en esa tradición estructuralista, este trabajo analiza la evolución del patrón de desarrollo productivo en América Latina. A la luz de un ejercicio de estadística descriptiva guiado por los modelos dualistas y la contabilidad del crecimiento, se relaciona la desaceleración de productividad observada desde dos decenios en el nivel macroeconómico con la evolución relativa de los diversos sectores productivos y la recomposición de la fuerza de trabajo. En el camino, se examinan también la transición productiva hacia la industrialización y la terciarización de las economías, incursionando en temáticas afines como la competitividad internacional y la equidad. La comparación con los países asiáticos de industrialización más o menos temprana sirve de benchmarking para afianzar el diagnóstico regional. Antes de concluir, el el trabajo hace una reevaluación del modelo conceptual inicial, con los hechos estilizados y las regularidades estadísticas surgidas del análisis fenomenológico.

\section{Marco conceptual y contable del estudio}

El análisis de la evolución de largo plazo de la productividad global se ha basado desde los años sesenta en modelos agregados de un solo sector, al estilo de Solow. Este enfoque privilegia el análisis de los aspectos cuantitativos de los factores de 


\section{HUBERT ESCAITH}

producción (capital y trabajo) en una economía que supone homogeneidad y flexibilidad de los factores de producción, y exogeneidad del progreso técnico.

El debate inicialmente concebido desde una perspectiva de economías maduras acabó por englobar también el análisis de las economías en vías de desarrollo. La renovación de este campo teórico en los últimos quince años no ha cambiado el uso de modelos muy agregados, de un solo sector, aun para estudiar economías en transición. ${ }^{1}$ El modelo de Solow es ahora reconocido por su flexibilidad para acomodar varios enfoques alternativos (Durlauf y Quah, 1998) y la contabilidad del crecimiento que se deriva de él ha sido aplicado con éxito en América Latina (Hofman, 2000). Sin embargo, los modelos agregados no permiten explorar todas las interacciones y disfunciones propias a economías heterogéneas, características de los países en desarrollo.

Las escuelas estructuralistas ponen, al contrario, el énfasis en la heterogeneidad estructural de esas economías y en la alta viscosidad de los cambios intersectoriales, creando diferencias persistentes en los rendimientos marginales según los sectores productivos. El ejemplo más conocido es el modelo de Lewis (1954), que valió a este economista caribeño el premio Nobel de economía en 1979. La transformación de la estructura productiva y la eliminación de la heterogeneidad estructural son centrales para superar la condición de subdesarrollo, reducir el excedente de mano de obra y liberarse de la ley de hierro que limita los ingresos en niveles de subsistencia.

\section{Modelo conceptual}

La metodología de descomposición que empleamos en este ensayo se inspira de la corriente dualista. Consideramos una economía con dos sectores de producción, el primero tradicional y de baja productividad del trabajo $\left(\mathrm{S}_{1}\right)$, el segundo moderno y de productividad alta $\left(\mathrm{S}_{2}\right)$.

$$
\mathrm{Y}=\mathrm{Y}_{1}+\mathrm{Y}_{2}
$$

$$
\begin{aligned}
& Y=\text { PIB total } \\
& Y_{1}=\text { Valor agregado del sector } 1 \\
& Y_{2}=\text { Valor agregado del sector } 2
\end{aligned}
$$

siendo L la fuerza de trabajo empleada. Podemos definir con las mismas convenciones:

1 Hay excepciones a esta tendencia, véase Ranis (2003) para una revisión del debate y Ros (2000) para un análisis de las teorías y modelos. 


$$
\mathrm{L}=\mathrm{L}_{1}+\mathrm{L}_{2}
$$

A cualquier instante del tiempo $\mathrm{t}=\mathrm{T}$, tenemos:

$$
\mathrm{P}^{\mathrm{T}}=\mathrm{Y}^{\mathrm{T}} / \mathrm{L}^{\mathrm{T}}=\left[\mathrm{Y}_{1}{ }^{\mathrm{T}} / \mathrm{L}_{1}{ }^{\mathrm{T}} \cdot \mathrm{L}_{1}{ }^{\mathrm{T}} / \mathrm{L}^{\mathrm{T}}\right]+\left[\mathrm{Y}_{2}{ }_{2}^{\mathrm{T}} / \mathrm{L}_{2}{ }^{\mathrm{T}} \cdot \mathrm{L}_{2}{ }_{2}^{\mathrm{T}} / \mathrm{L}^{\mathrm{T}}\right]
$$

Podemos reescribir (3) como:

$$
\mathrm{P}^{\mathrm{T}}=\mathrm{P}_{1}^{\mathrm{T}} \mathrm{S}_{1}^{\mathrm{T}}+\mathrm{P}_{2}^{\mathrm{T}} \mathrm{S}_{2}^{\mathrm{T}}
$$

en la cual:

$\mathrm{P}_{\mathrm{i}}^{\mathrm{T}}$ : nivel del valor agregado por persona empleada en el sector $\mathrm{i}=1$ o 2 al instante $\mathrm{t}=\mathrm{T}$

$\mathrm{S}_{\mathrm{i}}^{\mathrm{T}}$ : participación del sector $\mathrm{i}(\mathrm{i}=1$ o 2$)$ en la población activa empleada en $\mathrm{t}=\mathrm{T}$.

La economía es abierta, y el sector moderno, que usa tecnologías y métodos de frontera, es competitivo internacionalmente al sistema de precios prevaleciente. El desarrollo productivo y la competitividad internacional se analizan, sin embargo, como un fenómeno estructural: el sector moderno no puede exportar si el promedio de la economía nacional no ha alcanzado el nivel de competitividad (excluimos del campo analítico las pequeñas enclaves exportadoras).

La Gráfica 1 muestra de manera esquemática los efectos cruzados de un cambio de composición de la fuerza de trabajo entre actividades tradicionales y modernas (sectores 1 y 2 , respectivamente) y un aumento de productividad en el sector moderno. En el primer panel, el eje vertical corresponde a una situación en la cual $100 \%$ de la fuerza laboral está en el sector tradicional $\left(S_{1}=1\right)$. El eje horizontal a la situación cuando $100 \%$ del empleo ha migrado hacia el sector moderno $\left(\mathrm{S}_{2}=1\right)$. $\mathrm{O}$ sea, a medida que se recompone la fuerza de trabajo entre 1 y 2 , la productividad media cambia, conformando un círculo si la productividad del sector 2 es igual a la del sector $1\left(\mathrm{P}_{2}=\mathrm{P}_{1}\right)$ y un elipse cuando $\mathrm{P}_{2}>\mathrm{P}_{1}$.

La productividad media (Y/L) inicial corresponde a la longitud del segmento OA del cuadrante superior de la gráfica. A medida que la fuerza de trabajo migra, decrece $\mathrm{L}_{1}$ y aumenta $\mathrm{L}_{2}$. En el curso de la transición, la economía cruza el umbral de productividad media que le permite ser competitiva internacionalmente, entrando en el cono de competitividad.

Al final del proceso, la productividad media corresponde al segmento OB, en ausencia de cambio de la productividad sectorial. 


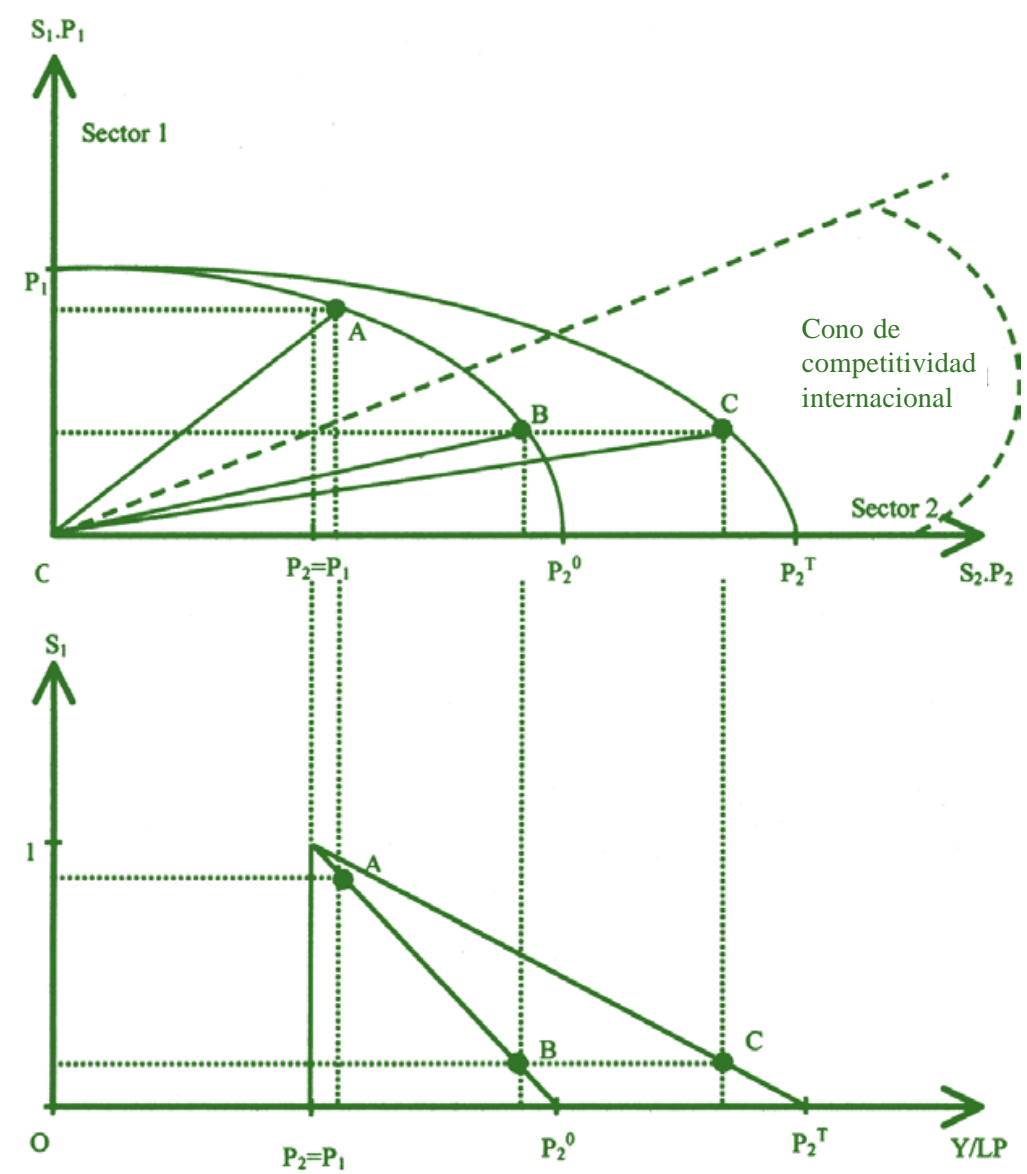

Gráfica 1. Productividad y composición de la fuerza de trabajo en un sistema dualista

$\mathrm{OA}>\mathrm{OB}$, o sea, a medida que la fuerza de trabajo migra del sector tradicional al sector moderno, la productividad media del trabajo aumenta, aun en ausencia de mejora tecnológica en el nivel sectorial. Llamaremos efecto de recomposición estructural al impacto de dicha migración sobre la productividad media del trabajo. Esta situación corresponde al cambio de la productividad media a lo largo del arco $\mathrm{AB}$ en la Gráfica 1.

Pero si la productividad del sector moderno aumenta $\left(\mathrm{P}_{2}{ }^{\mathrm{T}}>\mathrm{P}_{2}{ }^{0}\right)$, la productividad media del trabajo $\mathrm{P}^{\mathrm{T}}$ crece hasta OC. Llamaremos intrínseco a este efecto del aumento de la productividad de un sector sobre la productividad promedio.

El segundo panel de la gráfica permite observar esta dinámica desde otro ángulo. El eje vertical representa la proporción de trabajadores en el sector tradicional (por construcción, la proporción de trabajadores en el sector moderno es dada por el complemento a 1). El eje horizontal muestra la productividad media del trabajo en el con- 
junto de la economía. Cuando $\mathrm{P}_{2}=\mathrm{P}_{1}$, la productividad media es constante, y el conjunto de los puntos define un segmento vertical. Cuando $\mathrm{P}_{2}>\mathrm{P}_{1}$, este conjunto define segmentos de inclinación variable en función de la diferencia entre $\mathrm{P}_{2} \mathrm{y}_{1}$.

Este esquema muy simple permite, sin embargo, abordar varios conceptos importantes además de ilustrar el efecto de recomposición estructural sobre la productividad media del trabajo. Además de introducir la noción de competitividad internacional, esta descomposición tiene prolongaciones interesantes en materia de distribución del ingreso si aceptamos la hipótesis de que los salarios en cada sector son proporcionales a la productividad intrínseca del trabajo. En el modelo simple de dos sectores con ingresos homogéneos dentro de cada sector, la curva de Lorenz forma un triángulo con la diagonal principal. En el panel superior de la gráfica, se puede mostrar que el coeficiente de concentración de Gini varía como la diferencia entre el rectángulo cuya diagonal es definida por la productividad media (v.g., segmento $\mathrm{OA}, \mathrm{OB}, \mathrm{OC}$ ) y el rectángulo inscrito de la misma altura $\mathrm{L}_{1} \mathrm{P}_{1}$, pero de longitud $\mathrm{L}_{2} \mathrm{P}_{1}$ es decir, lo que sería la situación en caso de igualdad de productividad entre los dos sectores $\left(\mathrm{P}_{2}=\mathrm{P}_{1}\right)$. $^{2}$

$\mathrm{El}$ proceso de cambio estructural induce una curva en $\mathrm{U}$ invertida de Kuznets. $\mathrm{Al}$ inicio, cuando todos los trabajadores están en el sector tradicional, los ingresos son iguales, aunque bajos. A medida que la composición estructural del trabajo se modifica a favor del sector moderno, sube el ingreso medio de la población en un contexto de creciente diferenciación salarial. Cuando la mayoría del empleo se encuentra en el sector moderno $\left(S_{2} \geq S_{1}\right)$, sigue creciendo el ingreso promedio, pero ahora en un contexto de disminución de la desigualdad. Mientras persiste el dualismo del mercado laboral, sin embargo, todo aumento de la productividad del sector moderno (por ejemplo cuando se pasa de B a C) se traducirá en un aumento del coeficiente de Gini. Finalmente, cuando todos los trabajadores están en el sector moderno, la economía presenta nuevamente una situación de equidad de la distribución del ingreso salarial, si suponemos que todos los empleos en el sector moderno son idénticos. ${ }^{3}$

$2 \quad I_{\mathrm{c}}$ siendo el coeficiente de concentración de Gini

$$
I_{c}=1 /(N Q) . \Sigma_{j}\left[\Sigma_{i<j} n_{i} n_{j}\left(x_{j}-x_{i}\right)\right]
$$

$n_{i} y_{j}=$ proporción de la población en la clase i y j; $x_{i} y_{j}=$ ingreso medio en la clase i y $j$. En el caso presente, la población total $\mathrm{N}$ y el ingreso total $\mathrm{Q}$ son normalizados y $\mathrm{NQ}=1$.

$$
\mathrm{I}_{\mathrm{c}}=\mathrm{S}_{1} \mathrm{~S}_{2}\left(\mathrm{P}_{2}-\mathrm{P}_{1}\right)
$$

Recordando que $\left(\mathrm{P}_{2}-\mathrm{P}_{1}\right) \geq 0, \mathrm{P}_{1}+\mathrm{P}_{2}=1, \mathrm{y}_{1}+\mathrm{S}_{2}=1$, se verifica que $\mathrm{I}_{\mathrm{c}}$ es una función creciente de $\left(\mathrm{P}_{2}-\mathrm{P}_{1}\right)$ sobre el intervalo [0;1]. Para cualquier valor no nulo de $\left(\mathrm{P}_{2}-\mathrm{P}_{1}\right), \mathrm{I}_{\mathrm{c}}$ es máximo en el punto $S_{1}=S_{2}=1 / 2$.

3 La diferenciación salarial en función de la productividad laboral no es propia de la escuela neoclásica, y es conciliable con situaciones de excedente de mano de obra cuando, por 


\section{HUBERT ESCAITH}

\section{Descomposición multisectorial}

Se puede pasar sencillamente de la representación gráfica del cambio de productividad a una expresión aritmética. Partiendo de la ecuación (4), en ausencia de progreso técnico en el sector tradicional $\left[\left(\mathrm{P}_{1}^{\mathrm{T}}-\mathrm{P}_{1}{ }^{0}\right)=0\right]$, la variación de $\mathrm{P}^{t}$ entre $\mathrm{t}=0 \mathrm{y} \mathrm{t}=\mathrm{T}$ se descompone de la manera siguiente:

$$
\left(\mathrm{P}^{\mathrm{T}}-\mathrm{P}^{0}\right)=\left(\mathrm{P}_{2}^{\mathrm{T}}-\mathrm{P}_{2}^{0}\right) \cdot \mathrm{S}_{2}^{\mathrm{T}}+\left[\left(\mathrm{S}_{1}^{\mathrm{T}}-\mathrm{S}_{1}{ }^{0}\right) \cdot \mathrm{P}_{1}{ }^{0}+\left(\mathrm{S}_{2}{ }^{\mathrm{T}}-\mathrm{S}_{2}{ }^{0}\right) \cdot \mathrm{P}_{2}{ }^{0}\right]
$$

Con cambio de productividad intrínseca en el sector tradicional, se obtiene:

$$
\begin{aligned}
& \left(\mathrm{P}^{\mathrm{T}}-\mathrm{P}^{0}\right)=\left[\left(\mathrm{P}_{1}{ }^{\mathrm{T}}-\mathrm{P}_{1}{ }^{0}\right) \cdot \mathrm{S}_{1}{ }^{\mathrm{T}}+\left(\mathrm{P}_{2}{ }^{\mathrm{T}}-\mathrm{P}_{2}{ }^{0}\right) \cdot \mathrm{S}_{2}{ }^{\mathrm{T}}\right] \\
& +\left[\left(\mathrm{S}_{1}{ }^{\mathrm{T}}-\mathrm{S}_{1}{ }^{0}\right) \cdot \mathrm{P}_{1}{ }^{0}+\left(\mathrm{S}_{2}{ }^{\mathrm{T}}-\mathrm{S}_{2}{ }^{0}\right) \cdot \mathrm{P}_{2}{ }^{0}\right]
\end{aligned}
$$

Los coeficientes $\mathrm{S}_{1}^{\mathrm{T}}$ y $\mathrm{P}_{1}^{0}$ ponderan la importancia de los cambios de cada variable. Esta descomposición se conoce en la literatura como fórmula de Fabricant (Maddison, 1952).

Para reducir el grado de arbitrariedad en la elección del año base, se optó por usar el promedio de los dos valores límites $\mathrm{t}=0 \mathrm{y} \mathrm{t}=\mathrm{T}$

$$
\begin{aligned}
& \left(\mathrm{P}^{\mathrm{T}}-\mathrm{P}^{0}\right)=\left[\left(\mathrm{P}_{1}^{\mathrm{T}}-\mathrm{P}_{1}^{0}\right) \cdot\left(\mathrm{S}_{1}{ }^{0}+\mathrm{S}_{1}{ }^{\mathrm{T}}\right) / 2+\left(\mathrm{P}_{2}{ }^{\mathrm{T}}-\mathrm{P}_{2}{ }^{0}\right) \cdot\left(\mathrm{S}_{2}{ }^{0}+\mathrm{S}_{2}{ }^{\mathrm{T}}\right) / 2\right] \\
& \quad+\left[\left(\mathrm{S}_{1}{ }^{\mathrm{T}}-\mathrm{S}_{1}{ }^{0}\right) \cdot\left(\mathrm{P}_{1}^{0}+\mathrm{P}_{1}{ }^{\mathrm{T}}\right) / 2+\left(\mathrm{S}_{2}{ }^{\mathrm{T}}-\mathrm{S}_{2}{ }^{0}\right) \cdot\left(\mathrm{P}_{2}^{0}+\mathrm{P}_{2}{ }^{\mathrm{T}}\right) / 2\right]
\end{aligned}
$$

Si el dualismo a la Lewis es atractivo por su sencillez conceptual, es demasiado reduccionista para un ejercicio de economía aplicada a la realidad productiva contemporánea que apunta a una multiplicidad de sectores productivos. En caso de $n$ sectores, se puede escribir:

$$
\left(\mathrm{P}^{\mathrm{T}}-\mathrm{P}^{0}\right)=\sum_{i=1}^{n}\left[\left(\mathrm{P}_{\mathrm{i}}^{\mathrm{T}}-\mathrm{P}_{\mathrm{i}}^{0}\right) \cdot\left(\mathrm{S}_{\mathrm{i}}^{0}+\mathrm{S}_{\mathrm{i}}^{\mathrm{T}}\right) / 2\right]+\sum_{i=1}^{n}\left[\left(\mathrm{~S}_{\mathrm{i}}^{\mathrm{T}}-\mathrm{S}_{\mathrm{i}}{ }^{0}\right) \cdot\left(\mathrm{P}_{\mathrm{i}}^{0}+\mathrm{P}_{\mathrm{i}}^{\mathrm{T}}\right) / 2\right]
$$

La primera suma del término de derecha representa la variación de productividad total atribuible a los cambios en la productividad intrínseca de los $n$ sectores. La segunda suma indica el aporte de la recomposición sectorial de la fuerza de trabajo. Si el empleo crece más en los sectores de alta productividad intrínseca, el

ejemplo, los salarios son de eficiencia o de reserva. En este caso, el sobresueldo pagado al em pleado para asegurar la calidad de su trabajo o su fidelidad a la empresa es proporcional a la pérdida potencial de va que significaría su defección. Si los puestos de trabajo creados en el sector moderno exigen calificaciones diferentes, la convergencia hacia un coeficiente de Gini bajo no es absoluta, pero es condicional a los niveles de capital humano. 
efecto neto será positivo; si los sectores de baja productividad son los receptores netos de empleo, el impacto neto de la recomposición factorial será negativo.

\section{Resultados y tipologías}

La descomposición (8) se aplicó a los datos de producto y de empleo sectoriales disponibles para nueve países de América Latina, entre 1960 y 2003. Por basarse en el valor agregado sectorial de la contabilidad nacional, la medición de la productividad no es independiente del vector de precios relativos y difiere de la productividad física del trabajo. El apéndice estadístico presenta los datos y sus fuentes, así como el tratamiento que se dio a los deflactores de precios.

\section{Evolución de la productividad laboral 1960-2003}

El valor agregado generado por puesto de trabajo ha tenido un crecimiento de largo plazo de $0.6 \%$ en promedio simple de los nueve países de la muestra. Sin embargo, esta media esconde realidades muy diferentes. Por ejemplo, la variación es globalmente negativa sobre el conjunto del periodo 1960-2003 en el caso de Venezuela. Excluyendo a esta economía, un outlier estadístico debido a la especificidad monoexportadora de su economía, el crecimiento promedio de la productividad anual es de $1.0 \%$ por persona empleada.

Llama también la atención la heterogeneidad de los valores agregados por trabajador que existía en la región en 1960, con un máximo equivalente a 21000 dólares en Venezuela y un mínimo de 1900 en Bolivia. La dispersión es menor en 2003, y el coeficiente de variación de los ingresos totales (salarios y utilidades) por trabajador disminuyó de 0.7 a 0.5 , pero ello se debe enteramente a la caída registrada por Venezuela. ${ }^{4}$ Excluyendo a este país, el coeficiente de variación se mantiene casi constante entre 1960 y 2003.

Se observa también una gran variabilidad de las tasas de crecimiento anual de la productividad laboral, entre los países o en el tiempo. El efecto de la recomposición estructural de la fuerza de trabajo es un factor muy importante en la variación total del producto por empleado, sobre el conjunto del periodo 1960-2003 (Cuadro 2). Esta variable estructural explica 70\% del cambio regional promedio (49\%, excluyendo a Venezuela). Subrayando la validez analítica del modelo de Lewis en la región, se observa que una mitad de esas ganancias provienen de la recomposición de la fuerza de trabajo agrícola: la expulsión (en términos de pérdida de participación en

4 La metodología propuesta no permite analizar esta economía rentista donde el concepto de ingreso nacional -incorporando la influencia de los términos del intercambio- es probablemente más importante que la desagregación sectorial del PIB. Para resolver este pro blema, Hernández (2006) introduce la renta petrolera al modelo de Solow. 


\section{HUBERT ESCAITH}

Cuadro 1

Valor agregado por sector de actividad, 1960 y 2003

(dólares a precios de 2000)

\begin{tabular}{|c|c|c|c|c|c|c|c|c|c|}
\hline & \multicolumn{4}{|c|}{ Valor agregado por trabajador } & \multicolumn{5}{|c|}{ Tasa anual de crecimiento } \\
\hline & & & & & & $1960-$ & $1960-$ & $1970-$ & $1990-$ \\
\hline & 1960 & 1980 & 1990 & 2003 & 2003 & 1970 & 1980 & 1990 & 2000 \\
\hline América Latina ${ }^{a}$ & 8224 & 11391 & 9440 & 10632 & 0.6 & 2.8 & 0.5 & -1.9 & 1.3 \\
\hline -Sin Venezuela & 6644 & 10227 & 8687 & 10275 & 1.0 & 3.0 & 1.4 & -1.6 & 1.6 \\
\hline Argentina & 13515 & 20020 & 16205 & 19836 & 0.9 & 2.8 & 1.1 & -2.1 & 2.7 \\
\hline Bolivia & 1935 & 3551 & 2706 & 2807 & 0.9 & 4.2 & 1.9 & -2.7 & 0.1 \\
\hline Brasil & 4644 & 8499 & 7815 & 8702 & 1.5 & 2.9 & 3.2 & -0.8 & 0.6 \\
\hline Chile & 6735 & 9545 & 9357 & 13622 & 1.7 & 2.5 & 1.0 & -0.2 & 3.5 \\
\hline Colombia & 3532 & 5196 & 5510 & 5915 & 1.2 & 2.2 & 1.7 & 0.6 & 0.8 \\
\hline Costa Rica & 7088 & 10551 & 9030 & 10879 & 1.0 & 2.6 & 1.4 & -1.5 & 1.3 \\
\hline México & 10317 & 16838 & 14040 & 14355 & 0.8 & 3.7 & 1.3 & -1.8 & 0.3 \\
\hline Perú & 5383 & 7613 & 4837 & 6087 & 0.3 & 2.8 & 0.7 & -4.4 & 1.6 \\
\hline Venezuela & 20866 & 20703 & 15464 & 13489 & -1.0 & 2.3 & -2.3 & -2.9 & -0.6 \\
\hline
\end{tabular}

${ }^{a}$ Promedio simple de los países

Fuente: véase Apéndice estadístico.

el empleo total) de empleos agrícolas causó una pérdida de potencial equivalente a $35 \%$ del aumento de productividad total, mientras su productividad intrínseca subió y aportó $17 \%$ del aumento total (23\% y $11 \%$, respectivamente, si se excluye a Venezuela).

La industria manufacturera, sector moderno por excelencia en el modelo de Lewis, aportó $22 \%$ del crecimiento de productividad promedio, resultante de un aumento de $33 \%$ de su productividad intrínseca. Sin embargo, sobre el conjunto del periodo analizado, este sector no ha creado empleos en cantidad suficiente para comportarse como lo esperado en un verdadero polo de desarrollo. Esta incapacidad de generar puestos de trabajo se traduce en una merma de $11 \%$ de su aporte al aumento de productividad laboral total.

El mayor aporte viene del sector financiero. Su contribución de $41 \%$ a la productividad media se origina casi íntegramente del efecto de recomposición estructural, sin aumento correlativo del va generado por puesto de trabajo. Finalmente, cabe señalar la simetría casi perfecta que existe entre el valor de las pérdidas de VA por puesto de trabajo en el sector de comercio y hotelería, y el aumento por efecto de recomposición del empleo.

$\mathrm{Al}$ analizar la situación de cada país en el Cuadro 2, llama particularmente la atención la gran heterogeneidad de las trayectorias nacionales en materia de productividad. El país de mayor crecimiento absoluto en el va por empleado ha sido Chile con 161 dólares por año, correspondiendo a una variación de $1.7 \%$ anual, seguido por Argentina (148 dólares y 1.1\%, respectivamente). En ambos casos, 
Cuadro 2

Variación anual y descomposición de la productividad laboral, promedio 1960-2003 (dólares de 2000)

\begin{tabular}{|c|c|c|c|c|c|c|c|c|c|}
\hline & \multicolumn{3}{|c|}{$\begin{array}{l}\text { Argentina } \\
\text { Prod. }\end{array}$} & \multicolumn{3}{|c|}{$\begin{array}{l}\quad B \text { ollivia } \\
\text { Prod. }\end{array}$} & \multicolumn{3}{|c|}{ Prod $B$ asil } \\
\hline & total & Intrínseca & Estructura & total & Intrínseca & Estructura & total & Intrínseca & Estructura \\
\hline Total PIB & 148 & 158 & -10 & 21 & -24 & 45 & 98 & 45 & 52 \\
\hline Agricultura & -24 & 3 & -27 & -1 & 6 & -7 & 1 & 27 & -26 \\
\hline Minas y canteras & 10 & 11 & -1 & 2 & 2 & -1 & 5 & 4 & 1 \\
\hline Industria manufacturera & 10 & 86 & -76 & 5 & 1 & 4 & 20 & 9 & 11 \\
\hline Servicios básicos & 9 & 13 & -4 & 2 & 0 & 1 & 5 & 5 & 0 \\
\hline Construcción & 3 & 5 & -2 & 0 & -1 & 2 & 7 & -3 & 10 \\
\hline Comercio, restaurantes y hoteles & 8 & -19 & 27 & -1 & -16 & 15 & -8 & -20 & 13 \\
\hline Transporte y comunicaciones & 7 & 13 & -6 & 5 & 1 & 4 & 8 & 6 & 1 \\
\hline Servicios financieros & 82 & 50 & 31 & 4 & -19 & 23 & 26 & 9 & 17 \\
\hline \multirow[t]{3}{*}{ Servicios sociales } & 45 & -1 & 46 & 6 & 0 & 5 & 36 & 11 & 25 \\
\hline & \multicolumn{3}{|c|}{$C h$ i l e } & \multicolumn{3}{|c|}{$\begin{array}{l}\text { Colombia } \\
\text { Prod. }\end{array}$} & \multicolumn{3}{|c|}{$\begin{array}{l}\text { Costa Rica } \\
\text { Prod. }\end{array}$} \\
\hline & total & Intrínseca & Estructura & total & Intrínseca & Estructura & total & Intrínseca & Estructura \\
\hline Total PIB & 161 & 157 & 5 & 57 & 40 & 16 & 86 & 11 & 75 \\
\hline Agricultura & 6 & 21 & -15 & -8 & 10 & -18 & -20 & 9 & -29 \\
\hline Minas y canteras & 5 & 36 & -31 & 6 & 5 & 1 & 0 & 0 & 0 \\
\hline Industria manufacturera & 22 & 47 & -25 & 9 & 11 & -2 & 38 & 27 & 11 \\
\hline Servicios básicos & 8 & 9 & -1 & 4 & 5 & 0 & 5 & 1 & 4 \\
\hline Construcción & 17 & 8 & 9 & 4 & 2 & 1 & 1 & -2 & 2 \\
\hline Comercio, restaurantes y hoteles & 9 & -13 & 23 & 4 & -21 & 25 & 10 & -41 & 52 \\
\hline Transporte y comunicaciones & 17 & 12 & 5 & 4 & 2 & 2 & 18 & 13 & 5 \\
\hline Servicios financieros & 55 & 16 & 40 & 17 & 15 & 2 & 16 & -13 & 29 \\
\hline \multirow[t]{3}{*}{ Servicios sociales } & 26 & 24 & 2 & 17 & 13 & 5 & 20 & 17 & 3 \\
\hline & \multicolumn{3}{|c|}{$M e ́ c x i r c o$} & \multicolumn{3}{|c|}{$\begin{array}{llll}P & e & r & \dot{u}\end{array}$} & \multicolumn{3}{|c|}{$\begin{array}{l}V e n e z u e l a \\
\text { Prod. }\end{array}$} \\
\hline & total & Intrínseca & Estructura & total & Intrínseca & Estructura & total & Intrínseca & Estructura \\
\hline Total PIB & 100 & -24 & 124 & 23 & -10 & 33 & -167 & -193 & 26 \\
\hline Agricultura & -26 & 1 & -26 & -10 & 1 & -11 & -21 & 10 & -30 \\
\hline Minas y canteras & -1 & 5 & -5 & 2 & 10 & -8 & -54 & -7 & -47 \\
\hline Industria manufacturera & 20 & 9 & 11 & 1 & 5 & -4 & -10 & -21 & 12 \\
\hline Servicios básicos & 3 & 1 & 1 & 3 & 3 & 0 & 4 & 3 & 1 \\
\hline Construcción & 6 & -7 & 13 & 3 & 3 & 0 & -6 & -10 & 4 \\
\hline Comercio, restaurantes y hoteles & 17 & -50 & 67 & 6 & -22 & 28 & -26 & -43 & 17 \\
\hline Transporte y comunicaciones & 28 & 15 & 13 & 6 & -2 & 8 & -27 & -42 & 14 \\
\hline Servicios financieros & 19 & -14 & 33 & 10 & 3 & 7 & -11 & -41 & 29 \\
\hline \multirow[t]{4}{*}{ Servicios sociales } & 35 & 15 & 20 & 2 & -10 & 13 & -21 & -47 & 26 \\
\hline & \multicolumn{3}{|c|}{ América Latina ${ }^{a}$} & mérica & Latina, sin & Venezuela ${ }^{a}$ & & & \\
\hline & Prod. & & & Prod. & & & & & \\
\hline & total & Intrínseca & Estructura & total & Intrínseca & Estructura & & & \\
\hline Total PIB & 58 & 18 & 41 & 87 & 44 & 43 & & & \\
\hline Agricultura & -11 & 10 & -21 & -10 & 10 & -20 & & & \\
\hline Minas y canteras & -3 & 8 & -11 & 4 & 10 & -6 & & & \\
\hline Industria manufacturera & 13 & 19 & -6 & 16 & 24 & -9 & & & \\
\hline Servicios básicos & 5 & 4 & 0 & 5 & 5 & 0 & & & \\
\hline Construcción & 4 & 0 & 4 & 5 & 1 & 4 & & & \\
\hline Comercio, restaurantes y hoteles & 2 & -27 & 30 & 6 & -25 & 31 & & & \\
\hline Transporte y comunicaciones & 7 & 2 & 5 & 12 & 7 & 4 & & & \\
\hline Servicios financieros & 24 & 1 & 24 & 29 & 6 & 23 & & & \\
\hline Servicios sociales & 18 & 2 & 16 & 23 & 9 & 15 & & & \\
\hline
\end{tabular}

a Promedio simple.

Prod. total: cambio en la productividad laboral total. 
este aumento de productividad corresponde al de la productividad intrínseca de los sectores y no a los efectos de la recomposición estructural de la mano de obra, que llegan incluso a ser negativos en Argentina. Cabe recordar que estos dos países están avanzados en su transición demográfica y el crecimiento poblacional es moderado (Lagos y Arriagada, 1998).

La fuerte presión demográfica permite, por el contrario, avanzar una explicación parcial de los magros resultados observados en Bolivia, con un alza promedio de la productividad de 21 dólares por año, correspondiendo a una progresión de $0.9 \%$ anual, y Perú (23 dólares y $0.3 \%$, respectivamente). En estas naciones, la variación en productividad intrínseca es negativa, y el efecto estructural predomina.

Existe una simetría entre Brasil y México, las dos economías de mayor peso en la región. Ambos países registraron aumentos de va por trabajador en torno a 100 dólares en promedio anual. Este aumento se reparte de manera equilibrada entre productividad intrínseca y efecto estructural en Brasil. En México, este último efecto domina y compensa una merma en la productividad intrínseca.

Si el ritmo y el origen del cambio de productividad laboral difieren mucho entre países, la heterogeneidad es también importante según la fase del ciclo económico. El análisis anual (Gráfica 2) permite apreciar las fluctuaciones cíclicas en la perspectiva de las tendencias globales. En particular, muestra claramente que el periodo de oro del crecimiento latinoamericano culminó con los años sesenta, ya que el progresivo agotamiento de este modelo de crecimiento y la desaceleración productiva iniciaron antes del choque petrolero de 1973 y de la ruptura de los acuerdos de Bretton Woods.

Se observa también que la profunda crisis iniciada con la deuda de 1982 dañó el componente intrínseco, sin afectar mayormente las ganancias productivas provenientes de la recomposición estructural. El colapso productivo tocó fondo en 1984; sin embargo, la variación de productividad se vuelve positiva solamente después de 1991, justificando el calificativo de década perdida que se dio a este periodo.

Las ganancias de productividad laboral por el efecto de cambio estructural de la mano de obra quedaron positivas durante 40 años y explican una parte significativa del aumento de la productividad laboral de largo plazo. Las ganancias de productividad debidas a los cambios estructurales son inferiores en periodos recesivos, pero se mantuvieron nítidamente positivas, aun durante la década perdida. Durante la fase de crecimiento alto observada en 1973-1981, los efectos estructurales fueron incluso mucho más importantes que las ganancias intrínsecas de productividad dentro de cada sector. Fue sólo durante la recesión posterior a 1998 que aparecieron por primera vez cambios estructurales de mano de obra que tuvieron efectos globalmente negativos sobre la productividad laboral promedio. 


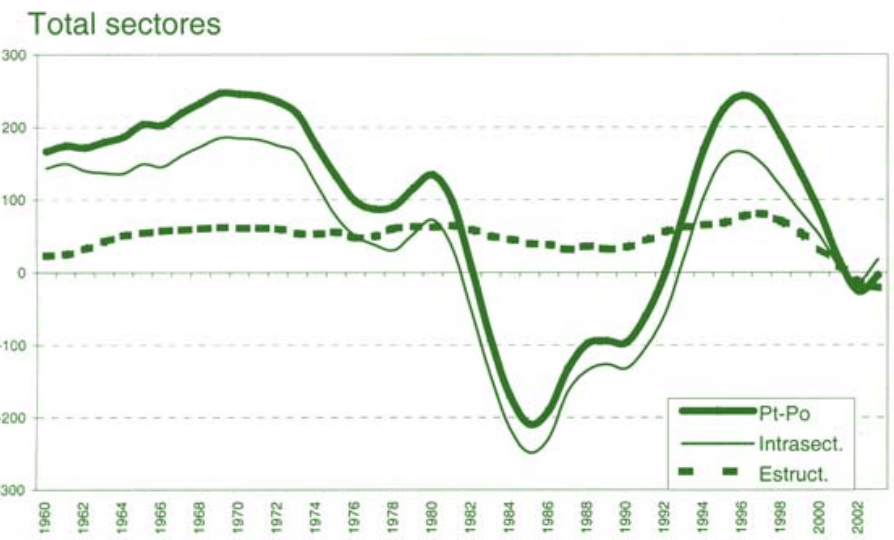

Gráfica 2. Evolución quinquenal de la productividad laboral y su descomposición, ${ }^{a}$ 1960-2003 (promedio regional sin Venezuela, dólares de 2000).

a Variación quinquenal anualizada, el año indicado corresponde al fin del lustro. Fuente: elaboración propia.

El quinquenio perdido que sucedió a las crisis asiática y rusa de 1997-1998 tocó fondo en 2002. Por primera vez en la historia de la región se observaron efectos estructurales negativos al más profundo de esta recesión: la recomposición intersectorial de la mano de obra aceleró el deterioro de la productividad intrínseca. A partir de 2003 se inició un nuevo ciclo económico, que no entra en el análisis de este ensayo.

\section{Definición de los ciclos}

La Gráfica 4 pone en evidencia que la productividad laboral es sensible a los ciclos y que el componente intrínseco lo es mucho más que el de recomposición estructural. En el siguiente recuadro se presentan algunos aspectos conceptuales que podrían determinar esa sensibilidad.

Es probable que existan relaciones cruzadas entre fluctuaciones de corto plazo y desarrollo de las fuerzas productivas subyacentes. Por ejemplo, la fuerza de la recuperación en los años noventa llegó a aumentos de productividad laboral superiores, en valor absoluto, a los observados en los años cincuenta y sesenta durante el periodo de oro del crecimiento regional. No obstante, dicho periodo duró más de 15 años, lo cual permitió consolidar los procesos de inversión y de creación de capacidad productiva en un ámbito de crecimiento con estabilidad, mientras la fase de alta ganancia de productividad observada en los años noventa ha sido mucho más breve y culminó en 1997. Incluso durante esa fase se registró una crisis de balanza de pagos en México. En esas condiciones, era difícil esperar que se cimentaran y consolidaran durablemente los nuevos proyectos productivos. Debido a la falta de visibilidad temporal y a la incertidumbre correlativa sobre el futuro de los mercados 
Recuadro 1

Productividad y ciclos económicos

Históricamente, el análisis del comportamiento dinámico de la productividad laboral se desarrolló principalmente en el sector industrial, y varios economistas encontraron regularidades estadísticas entre la productividad del trabajo y la tasa de crecimiento de la producción industrial. La asociación positiva entre ambos factores, denominada Ley de Fabricant, se haya verificado en varios de los países desarrollados. Además, el crecimiento de productividad suele acompañarse de un aumento del empleo en esas industrias. Las razones avanzadas para explicar esos fenómenos son eclécticas, y están generalmente asociadas al progreso técnico, a la sustitución de factores o a efectos externos (Scott, 1989).

No obstante, en el corto/mediano plazos, las variaciones de productividad pueden atribuirse también a variaciones cíclicas de la demanda. Éstas, en ausencia de una total flexibilidad del aparato productivo, hacen que las empresas se acerquen o se alejen de su frontera de producción potencial, dada la dotación - fija en el corto plazo — de factores productivos (Ley de Okun). Los movimientos que provienen de la esfera de la demanda pueden confundirse con los cambios más estructurales de oferta desarrollados en la esfera productiva. Obviamente, las relaciones de causalidad entre impulsos de demanda y de oferta son complejas y ambivalentes. Los periodos de demanda alta corresponden a fases de rápida acumulación, que permiten además incorporar nuevas tecnologías al acervo de capital. Sin embargo, es generalmente reconocido en la literatura del mainstream neoclásico y keynesiano que los impulsos de demanda están más relacionados con los cambios de corto plazo, mientras que los de oferta son persistentes en el largo plazo.

La persistencia de los impulsos de demanda en el largo plazo depende, por su parte, de la existencia de rendimientos crecientes a escala.* Sin embargo, los efectos positivos de la demanda durante la fase alta del ciclo se cancelan en la fase baja. No es así en el enfoque de oferta: la sobreinversión de la fase de auge determina una subutilización del capital en la fase baja (Ley de Okun), sin destrucción de sobrecapacidad. Determinar el efecto neto entre factores de oferta y de demanda es un debate empírico no resuelto que no entra en la perspectiva de este trabajo.

* Una importante literatura poskeynesiana — basada en la reinterpretación de la Ley de Verdoorn por Kaldor en los años sesenta-, proclama la naturaleza intrínsecamente endógena y acumulativa del crecimiento de largo plazo. Para una evaluación, véase McCombie et al., (2002), y Gordon (1991).

potenciales, es probable que haya predominado en la década de los noventa la inversión de tipo cualitativo (mejorar la productividad y disminuir los costos) más que la inversión de tipo cuantitativo (extender la producción y ganar mercados).

Para incorporar en el análisis los efectos cíclicos se buscó, en primera instancia, medir los cambios en la productividad a lo largo de un ciclo económico completo. Luego, se dividió cada ciclo en sus dos fases sucesivas de auge y recesión, para poner en evidencia las simetrías y asimetrías que podrían existir entre sectores.

La definición del ciclo que adoptamos aquí se basa principalmente en consideraciones macrofinancieras que determinan las modalidades de la acumulación de capital y de su financiamiento. Coincide con las grandes fases de entrada y salida de los flujos de capital externo, uno de los factores claves del modo de crecimiento económico en América Latina. Se determinaron tres grandes periodos, que corresponden a distintos regímenes macroeconómicos regionales e internacionales:

- 1960-1972: este periodo corresponde al sistema internacional de Bretton-Woods, con tipo de cambio fijo, poca movilidad del capital y relativa estabilidad macro- 
económica. En este lapso de crecimiento sostenido por un entorno internacional favorable, la inversión está básicamente financiada por el ahorro interno;

- 1973-1990: nueva modalidad del sistema internacional, con mayores movimientos de capital financiero - en particular bancario- hacia los países en vías de desarrollo e inestabilidad nominal. Ese periodo cubre un ciclo económico completo que corresponde a la fase de crecimiento alto y endeudamiento creciente,

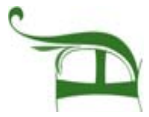
hasta inicios de los años ochenta, y su posterior ajuste luego de la crisis de la deuda en 1982. Entonces, el ciclo se divide en su fase de auge, de 1973 a 1981, y de recesión entre 1982 y 1990.

- 1991-2003: periodo posreformas, con el regreso del capital privado después de los Acuerdos Brady, pero con modalidades diferentes de canalización del ahorro externo hacia la región (preeminencia de los papeles financieros y de la inversión extranjera directa), y mayor volatilidad de los ciclos expansión-ajustes. Se pueden distinguir las dos fases del ciclo de la siguiente manera: una de crecimiento acelerado, hasta la crisis de las economías emergentes de 1997-1998, y un lapso de estagnación y recesión hasta 2003, primer año de recuperación.

Obviamente, no todas las naciones se insertan de la misma manera en la economía global ni son vulnerables a los mismos choques externos. Es entonces de esperar que los ciclos macrofinancieros y su transmisión a la esfera real no sean idénticos entre los países de la región. Pero esa determinación exógena presenta ventajas metodológicas al momento de identificar e inferir posibles relaciones de causalidad. Siendo una caracterización independiente del fenómeno real por estudiar, ayuda en no caer en la trampa epistemológica del post hoc ergo propter hoc.

El Cuadro 3 muestra la evolución de la productividad laboral total por varios subperiodos de 1960 a 2003. Para una lectura sintética del cuadro, comparamos dos a dos los lapsos de auge (1973-1981, 1991-1997) y los de desaceleración (19821990, 1998-2003).

El periodo 1960-1972 fue de crecimiento sostenido, pero no dio lugar a un posterior proceso de corrección o crisis (véase nuevamente la Gráfica 4). Por lo tanto, puede servir de referencia, una suerte de edad dorada de crecimiento alto y sostenible desde una perspectiva macroeconómica. La fase de auge del ciclo 19911997 fue más dinámica en términos de productividad laboral (197 dólares de aumento anual, 216 si se excluye a Venezuela) que la de 1973-1981 (14 y 89 dólares, respectivamente).

Muy temprano, la industria dejó de absorber mano de obra. A partir de la década de los setenta, su peso relativo en cuanto a la generación de puestos de trabajo disminuyó. Esa tendencia se aceleró, incluso durante la fase de recuperación de los 


\section{HUBERT ESCAITH}

60

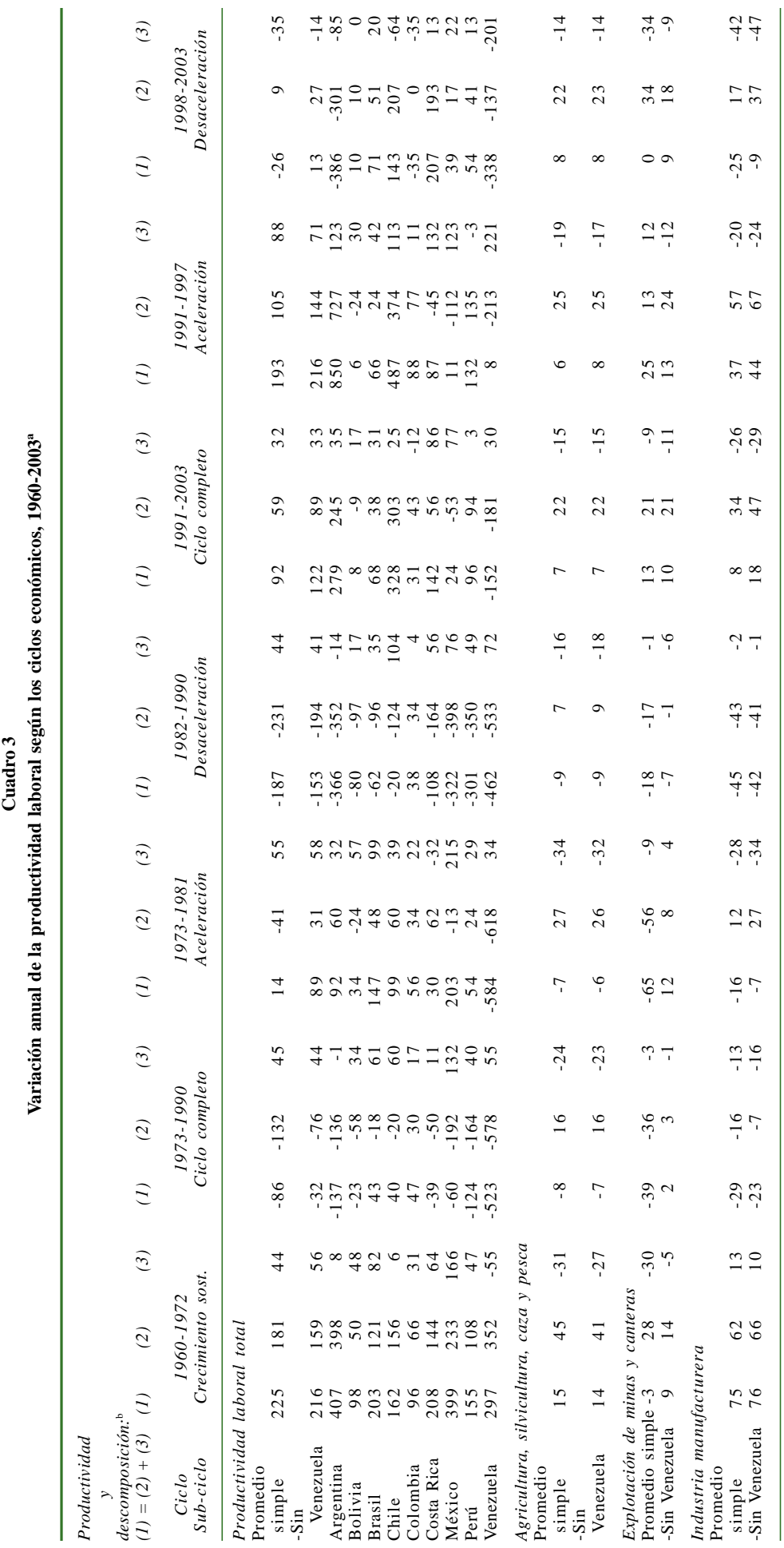


INDUSTRIALIZACIÓN TRUNCADA Y TERCIARIZACIÓN SUSTITUTIVA

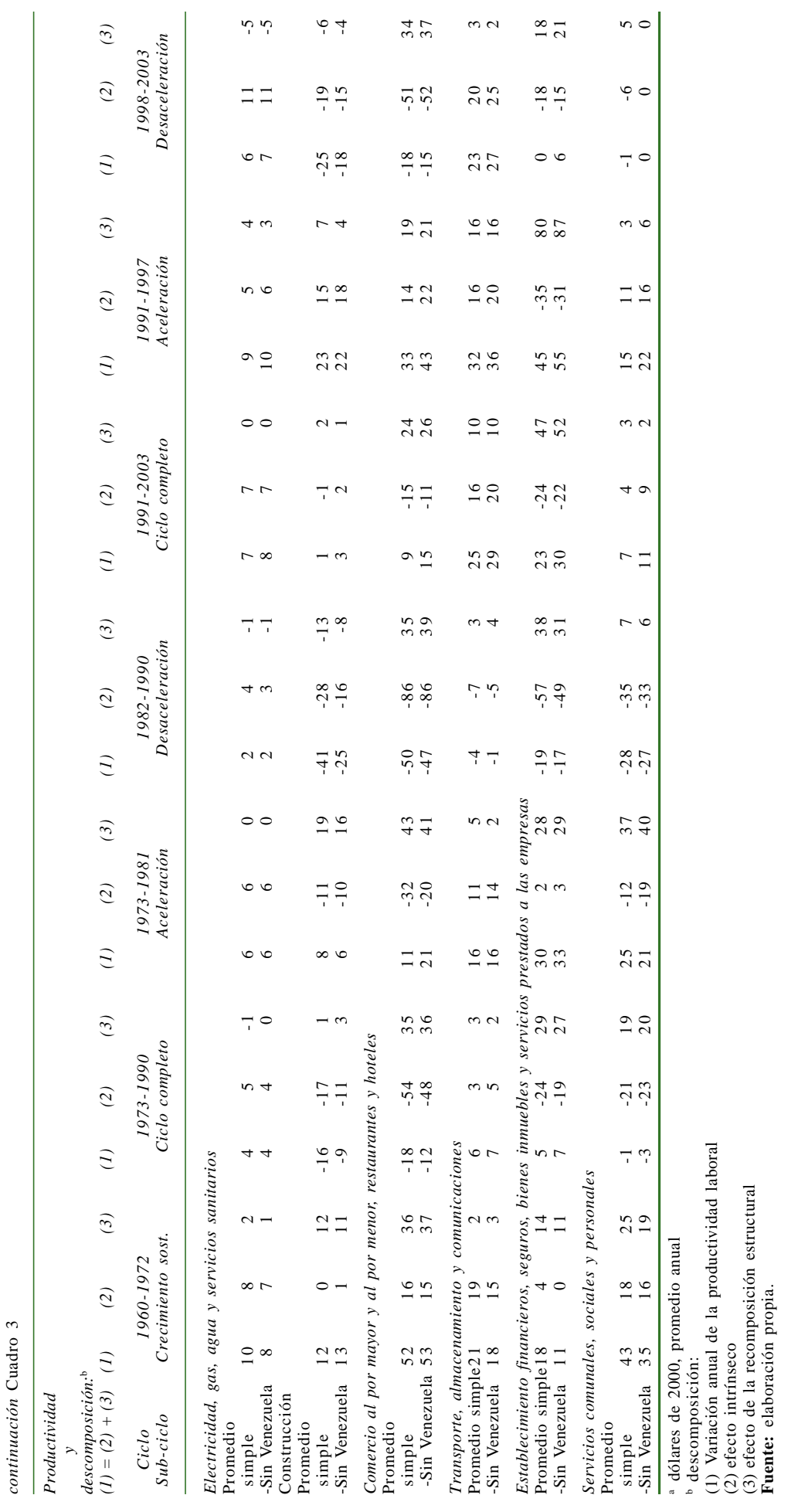

Vol. 37, núm. 147, octubre-diciembre / 2006

Desarrrollo 


\section{HUBERT ESCAITH}

años noventa cuando se inició un proceso de intensificación, con alto crecimiento de la productividad intrínseca y disminución del peso relativo en la estructura de empleo. También se observa que no se ha agotado la función de reserva de mano de obra de la agricultura. Ese sector sigue expulsando mano de obra, incluso en el periodo más reciente. Pero ahora, ese fenómeno viene acompañado de un aumento notable de su productividad intrínseca, una de las más altas entre los diversos sectores productivos.

Fueron entonces los sectores de comercio y, en menor proporción, de servicios financieros que tomaron la función absorbente de la mano de obra, con un aumento de los empleados, pero una merma de la productividad intrínseca. Los servicios básicos y la construcción, por su parte, no muestran cambios notorios en su productividad intrínseca ni en la estructura de empleo; con respecto de este último factor, sin embargo, la construcción muestra mayor sensibilidad al ciclo económico.

En promedio, durante los noventa los cambios en la composición estructural de la fuerza de trabajo representaron todavía la mitad de las ganancias de productividad. Al juzgar por la importancia de los efectos estructurales, las economías latinoamericanas están todavía en una fase de transición. Este último aspecto llama la atención, por la expectativa de que los efectos de composición sean menos importantes a medida que las economías se vuelvan más avanzadas en su proceso de transición hacia el steady state representado por una función de producción única à la Solow.

Todo indica lo opuesto: que persiste la heterogeneidad productiva en las economías regionales. Sin embargo, este dualismo no se puede reducir hoy en día a la dicotomía sector tradicional-sector moderno. Si bien es cierto que la agricultura conserva en varios países características tradicionales, las tecnologías y la productividad en este sector han mejorado muy rápidamente en los últimos veinte años.

Al contrario, algunos síntomas dejan pensar que se trata de un fenómeno más bien vinculado a la dinámica de los sectores moderno y urbano. Hemos notado, en particular, que se observaron por primera vez efectos estructurales negativos durante la fase recesiva del ciclo 1991-2003. ¿Qué pasó durante el quinquenio perdido que no se dio durante la década perdida?

La descomposición sector por sector aporta elementos de respuesta a esta pregunta. A diferencia de lo ocurrido en 1982-1990, la productividad intrínseca siguió aumentando, pero los sectores de alta productividad laboral (por ejemplo, la manufactura, minería, servicios de infraestructura y telecomunicaciones) expulsaron la mano de obra a medida que aumentaban su rentabilidad. ${ }^{5}$ Casi todo el empleo

5 Por ejemplo, mientras la industria manufacturera ganaba todavía 17 dólares de valor agre gado adicional por cada trabajador durante esta recesión, perdía 42 dólares debido a la reducción del peso relativo del empleo manufacturero en el total de los activos. 
Recuadro 2

Los empleos en el sector informal: nuevo sector de subsistencia

Medido a precios de 2000, el valor agregado generado por puesto de trabajo en el sector comercio era de 14600 dólares en 1960 y se redujo a 6900 en 2003, o sea, una reducción de 1.7\% anual. El sector de las cuentas nacionales incluye, además, del comercio al por menor, el comercio al por mayor, los restaurantes y los hoteles. Estas últimas actividades requieren, por lo general, de inversiones fijas relativamente más importantes que en el sector minorista, pero se prestan también a la informalidad. Sin embargo, sería erróneo limitar esa tendencia al sector comercio. Según Weller (2005), en todas las categorías de empleo urbano se incrementó el componente informal (trabajo por cuenta propia no profesional, incluido el familiar no remunerado, el de microempresas y el ser-vicio doméstico). La participación promedio del sector informal en el empleo urbano aumentó de $43 \%$ en 1990 a 47\% en 2003. Los ingresos laborales medios del sector formal y los del informal se han ampliado en los años noventa de 59 a 72\%, en el promedio regional. Al mismo tiempo, ha aumentado mucho el desempleo abierto, sobre todo durante la fase declinante del ciclo, a partir de 1998.

Por lo tanto, estamos confrontados al surgimiento e instalación de un nuevo sector de subsistencia, que viene a absorber la mano de obra en excedente, que no encontró empleo en el sector urbano formal, el llamado sector moderno del modelo de Lewis. Obviamente, esta tendencia global esconde diferencias importantes y no siempre el sector informal cumple solamente una función residual. Es en particular el caso de México donde los ingresos informales pueden superar 30\% a los del sector formal y la participación en esas actividades corresponden, en parte, a estrategias de optimación microeconómica (Perry y Olarreaga, 2006).

Sin embargo, esos casos son minoritarios y el aumento de la informalidad en los últimos años ha coincidido con una sobreoferta de trabajo y un alza del desempleo.* Incluso cuando la informalidad no es sinónimo de subsistencia, queda siendo una ruptura sistémica con el modelo à la Lewis, ya que impide la convergencia hacia una sociedad integrada. La pérdida de ingresos fiscales debilita, en particular, la ejecución de políticas sociales y acentúa la precariedad de los sistemas de pensiones por repartición.

* A prueba de ello mejoraron los indicadores de empleo con el inicio del nuevo ciclo económico después de 2003. La tasa de desempleo cayó en 2005 de $10.2 \%$ a 9.1\%, su nivel más bajo desde mediados de los noventa. En esa fase de recuperación, el aumento del empleo se produjo en el sector formal de las economías y el volumen del empleo por cuenta propia se estancó (CEPAL, 2006).

creado lo fue en comercio, sector refugio que registra en paralelo una merma del valor agregado promedio. Si bien dicho sector había jugado ese mismo papel durante la década perdida, la reducción relativa de empleo de buena calidad en los sectores de alto valor agregado fue mucho mayor a finales de los años noventa.

Buena parte de los empleos de refugio creados en el sector comercial son de mala calidad e informales (trabajo negro, autoempleo), que no corresponden al sector moderno de Lewis. Estamos presenciando entonces un quiebre del proceso de convergencia hacia el mundo de unificación à la Solow de los mercados de trabajo y de capital. Esto se puede atribuir a una agravación del proceso de informalidad, como estrategia de subsistencia que adoptaron los más vulnerables para enfrentar los efectos de la crisis. Este fenómeno está presente con varios grados de agudización en todos los países de la región, promoviendo una nueva forma de dualismo productivo y social (Weller, 2005; Cimoli et al., 2006; Ros, 2005). Este 
enfoque multisectorial concuerda también en sus principales conclusiones con una investigación reciente sobre la curva de Kuztnets en la región (Sánchez, 2006).

\section{Sensibilidad de la productividad sectorial al ciclo económico}

¿Cuál es la reacción de los sectores a la volatilidad de los ciclos económicos? El objetivo de esta sección es aportar elementos de respuesta, al analizar la sensibilidad de la productividad sectorial a lo largo de las fases ascendentes y descendentes del ciclo económico.

Para simplificar la lectura de los resultados, se agruparon los de los nueve sectores de la contabilidad nacional en tres tipos:

- Sectores productores de bienes: agricultura, minería e industria manufacturera. Esos sectores producen bienes transportables (tradables) sometidos a la competencia externa, y entonces sensibles tanto a los cambios estructurales de apertura económica, como a los ciclos internacionales de precios.

- Servicios de infraestructura: construcción, servicios básicos, transporte y comunicaciones. Esos sectores son intensivos en capital y requieren, por lo general, de una mano de obra calificada.

- Servicios no especificados previamente (NEP) a hogares y empresas: comercio, finanzas, administración pública y servicios personales. Son, en su mayoría, sectores menos exigentes en capital y más vinculados con la demanda final y el bienestar de la población.

La Gráfica 3 permite observar los principales resultados. Los cuadrantes [a, b y c] descomponen la variación total entre los tres grandes grupos que aglomeran los sectores productores de bienes, de servicios de infraestructura y del resto de los servicios comerciales y sociales. Se observa particularmente bien la simetría casi perfecta existente entre los sectores productores de bienes y los servicios comerciales y sociales:

- Durante todo el periodo los efectos estructurales de los primeros fueron negativos, mientras que fueron nítidamente positivos para los segundos.

- Al contrario, la contribución del mejoramiento de la productividad intrínseca fue generalmente positiva en el caso de las industrias, excepto en la segunda mitad de los años ochenta. A partir de 1975, los sectores de servicios comerciales y públicos registraron valores negativos para este componente, e indicaron que la mayoría de los empleos creados fueron de bajo valor agregado, en comparación con el resto de la economía.

\section{Désarrollo}



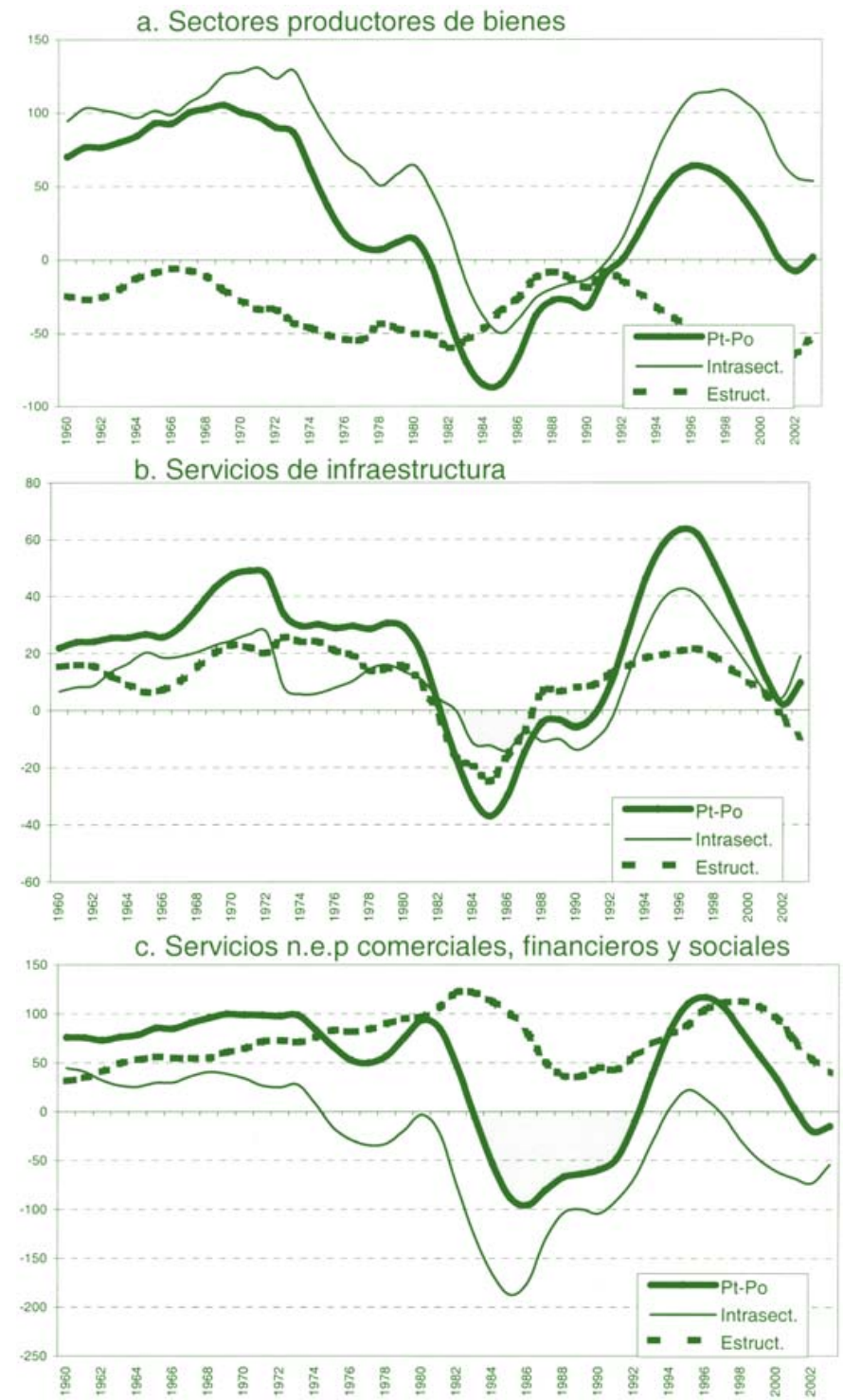

Gráficas 3a, 3b y 3c. Variación de la productividad laboral según grandes sectores de actividad, 1960-2003 (dólares de 2000).

Fuente: elaboración propia.

- Finalmente, el cuadrante [b] confirma que el sector de servicios de infraestructura es el menos volátil de todos. En este sector de servicios intensivos en capital, inversión y empleo parecen ser complementarios. Efectivamente, las contribuciones relativas del volumen de empleo y de la productividad intrínseca varían siempre en paralelo, a diferencia de los otros dos grupos en los cuales es poco común observar contribuciones de signo opuesto entre los dos componentes. 
Retomando la definición de ciclos y de sus fases expansivas y recesivas, podemos sintetizar con la definición de estos tres grandes sectores los resultados desagregados que fueron discutidos en la sección anterior.

\section{- Fases de crecimiento alto:}

Durante el lapso 1960-1972, la productividad intrínseca de los sectores productores de bienes creció mucho (121 dólares por año y por puesto de trabajo), aunque sufrió un retroceso de su participación en el empleo total, debido, en particular, al componente agrícola. Esa merma relativa redujo la generación de valor agregado sectorial en 22 dólares y la productividad total resultante subió en 98 dólares. En la misma cifra se incrementó la productividad laboral del sector servicios, pero con una descomposición diferente. Si bien los sectores de servicios comerciales y las administraciones públicas mejoraron su productividad intrínseca en 31 dólares por año, el mayor impacto se debe a una progresión del empleo (67 dólares). Contrario a lo esperado, la productividad de los servicios de infraestructura, intensivos en tecnología y capital, llegaron en último lugar tanto en término de productividad intrínseca, como de productividad total del trabajo.

La simetría entre los sectores productores de bienes para transacciones y los servicios se acentuó en la fase alta del ciclo 1973-1990. El sector de bienes no aportó nada a la productividad total de la economía, porque el alto crecimiento de su productividad intrínseca (61 dólares anuales por empleado) se vio totalmente compensado por una pérdida de empleo. Al contrario, el sector servicios ha creado muchos empleos nuevos. Pero al mismo tiempo se observa una merma de 35 dólares de valor agregado por empleo. El sector de infraestructura sigue sin incorporar mucha productividad intrínseca (apenas 10 dólares). Sin embargo, creció el empleo en ese sector, que también aporta 17 dólares al aumento anual promedio de la productividad laboral global.

Por el contrario, durante la fase expansiva del ciclo 1991-2003, este sector proveedor de servicios de infraestructura empezó a incorporar mayor productividad. Entre 1991 y 1997 se generaron anualmente 44 dólares adicionales de valor agregado por puesto de trabajo. En el mismo lapso, ese sector siguió creando empleo, e incrementó su contribución a la productividad laboral de la economía. Dicho crecimiento del valor agregado balanceado entre productividad intrínseca y empleo no se observó en los otros dos sectores: las industrias mejoraron mucho su productividad (117 dólares por año), pero perdieron empleos, y los servicios atrajeron muchos empleos, pero en un contexto de valor agregado por puesto de trabajo estancado.

\section{- Fases de crecimiento bajo y de recesión}

Esas fases corresponden a los años 1982-1990 y 1998-2003 que sucedieron a las de aceleración del crecimiento analizados anteriormente. Los servicios de infraestruc- 
tura aparecen como el sector de mayor resiliencia a la recesión, tanto en término de productividad intrínseca, como en cuanto a la productividad laboral total. Sin embargo, en ambos periodos su aporte fue marginalmente negativo (-6 dólares) en término de efecto empleo.

Los servicios comerciales confirman su papel de sector refugio: en ambos casos se observa un alza del empleo relativo, compensado por una caída de la productividad intrínseca. O sea, los empleos que se crearon en ese sector fueron de muy baja productividad.

El sector productor de bienes para transacciones tuvo, por el contrario, un desempeño muy diferenciado entre el decenio perdido de 1981-1990 y el sexenio perdido de 1998-2003. El decenio perdido correspondió a una clara recesión para este sector, que pese a una reducción del empleo, sufrió además una disminución de su productividad intrínseca. Con todo, ese sector contribuyó negativamente al retroceso de la productividad laboral total.

Al contrario, los sectores productores de bienes enfrentaron la recesión de 19982003 con una racionalización productiva que se tradujo en una reducción significativa del aporte por volumen de empleo (restando 70 dólares a la productividad nacional global), pero redondeó en una ganancia más que proporcional de productividad (78 dólares por puesto de trabajo). Podemos avanzar algunas hipótesis para explicar ese comportamiento.

Los sectores intensivos en recursos naturales se beneficiaron del contexto internacional muy favorable para los precios relativos que conocieron las exportaciones de bienes primarios a inicios de 2000. Ello incidió no sólo en la minería y en los hidrocarburos, pero también en la agricultura comercial. Al contrario, afectó negativamente al sector de industria manufacturera intensiva en mano de obra, que enfrentó un contexto de precios internacionales deprimidos por la creciente competencia asiática. El sector manufacturero regional reaccionó al adverso contexto de precios internacionales con una estrategia idéntica a la de los grupos industriales de los países desarrollados: focalizó el esfuerzo competitivo, redujo el empleo no estratégico e hizo inversiones de productividad para ganar competitividad en esos espacios. Es decir, luego del proceso de apertura de los años ochenta, la industria latinoamericana ha madurado y se comporta ahora como todas las empresas globalizadas.

\section{Comparación con Asia}

El rezago en materia de crecimiento económico ha sido una característica recurrente en las últimas décadas, cuando se compara América Latina con Asia. El llamado milagro asiático ha convertido a esta región en una suerte de modelo, y nos parece interesante comparar las dos regiones. La presente sección se apoya en los resultados 
de Van Ark y Timmer (2003), para nueve economías asiáticas desarrolladas o en vías de industrialización. ${ }^{6}$

El periodo más reciente estudiado por los autores va de 1985 a 2001, en el cual este último año fue también de estagnación para la mayoría de las economías asiáticas. El Cuadro 6 compara los resultados en ambas regiones, usando ese mismo periodo. En Asia, la productividad laboral ha crecido de un mínimo de $1.9 \%$ anual en Japón, hasta un máximo de $4.8 \%$, alcanzado en la vecina isla de Taiwán. Por el contrario, se observa una estagnación e incluso un retroceso del valor agregado por puesto de trabajo en casi la totalidad de los países latinoamericanos. Con un crecimiento anual promedio de $3.6 \%$ de su productividad laboral, Chile es la única economía latinoamericana cuyo desempeño global es comparable con la muestra de países asiáticos.

En el ámbito sectorial, se deben subrayar dos puntos interesantes para el efecto comparativo:

- Primero, la importancia del sector manufacturero para explicar la productividad total en Asia, tanto por su efecto intrínseco, como por su sostenida capacidad para crear nuevos empleos.

- Segundo, el sector de servicios comerciales mejora en Asia su productividad laboral, sin que crezca mucho el volumen relativo de empleo.

El círculo virtuoso asiático parece implicar entonces una industrialización creadora de empleos, con una modernización paralela del sector servicios. Ese efecto de arrastre puede ser directo, gracias a la creación de una demanda para las empresas de infraestructura (transporte, comunicación) y otros servicios a las empresas que acompaña el cambio de modelo productivo en la industria (por ejemplo, debido a la generalización de las prácticas de outsourcing y la creciente importancia de las funciones de marketing y de logística). El otro efecto, más indirecto, pasa por la emergencia de una clase media, con un poder adquisitivo suficiente para generar una demanda interna efectiva, en el sentido keynesiano. Japón evidentemente es el caso más acabado de ese proceso, con la creación en pocos decenios de un mercado interno suficientemente grande y sofisticado para sustentar y dinamizar lo que es hoy en día la segunda economía mundial.

En otras palabras, el sector industrial en Asia ha cumplido doble función, cualitativa y cuantitativa: las empresas cierran la brecha productiva y ganan competitividad externa, lo cual les permite exportar bienes de creciente valor agregado y generar

6 Corea, Hong Kong, India, Indonesia, Japón, Malasia, Singapur, Tailandia y Taiwán. 
un número significativo de empleos de buena calidad. En esa situación, el consumo intermedio de las empresas y la masa salarial industrial permiten a su vez desarrollar un mercado interno con el poder adquisitivo suficiente para sostener la dinámica del sector servicios. La terciarización de las economías asiáticas es complementaria al proceso de industrialización, a tal punto que esas economías conservan una orientación industrial.

El cuadro es totalmente diferente en América Latina. La terciarización creciente de sus economías revela más la incapacidad del sector manufacturero de ganar a la vez competitividad y mercados. Por lo tanto, el proceso de modernización industrial no ha podido desarrollar una capacidad suficiente de arrastre directo o indirecto hacia el resto de la economía. Eso se traduce en un subempleo estructural y la aparición de un sector terciario de subsistencia, con precariedad y baja productividad del empleo.

Si retomamos el modelo inicial que ha guiado este ensayo, podemos avanzar que la terciarización de las economías asiáticas ha sido virtuosa, y corresponde al pronóstico del modelo dualista de Lewis. Además, dichas economías han transitado hacia el cono de competitividad internacional. Al contrario, la aparición de un nuevo dualismo en América Latina traduce un cuadro patológico que dificulta transitar hacia las zonas de competitividad internacional y de menor desigualdad de ingreso.

En muchos aspectos, entonces, la terciarización en América Latina es sustitutiva de la industrialización y consolida los patrones de polarización social. Como persisten al mismo tiempo rasgos importantes del anterior sector tradicional, en particular en las poblaciones rurales marginales e indígenas, podemos caracterizar la situación latinoamericana como trialismo. La Gráfica 4 sintetiza en un esquema triangular la dinámica diferencial de Asia y América Latina.

Cabe subrayar aquí que el diagnóstico de un cuadro de persistente dualismo en América Latina es invariante a la escala de análisis y se reproduce dentro de los principales sectores de actividad.

Existe, por ejemplo, gran número de estudios sobre el dualismo interno al sector agrícola. En América Latina hoy suelen coexistir una agricultura campesina tradicional con actividades comerciales muy competiti-vas internacionalmente, que operan cerca de $-\mathrm{O}$ en - la frontera productiva. Para la región, la productividad de la tierra aumenta un promedio anual de $2 \%$, que revela la sustitución de mano de obra por capital y la intensificación del uso de la tierra. Sin embargo, persiste una heterogeneidad productiva en ese sector, en particular en relación con los mercados de exportación, ya que sólo un grupo relativamente reducido de agricultores participa directa o indirectamente en las exportaciones, vinculados a mercados (de exportación) 


\section{HUBERT ESCAITH}

70

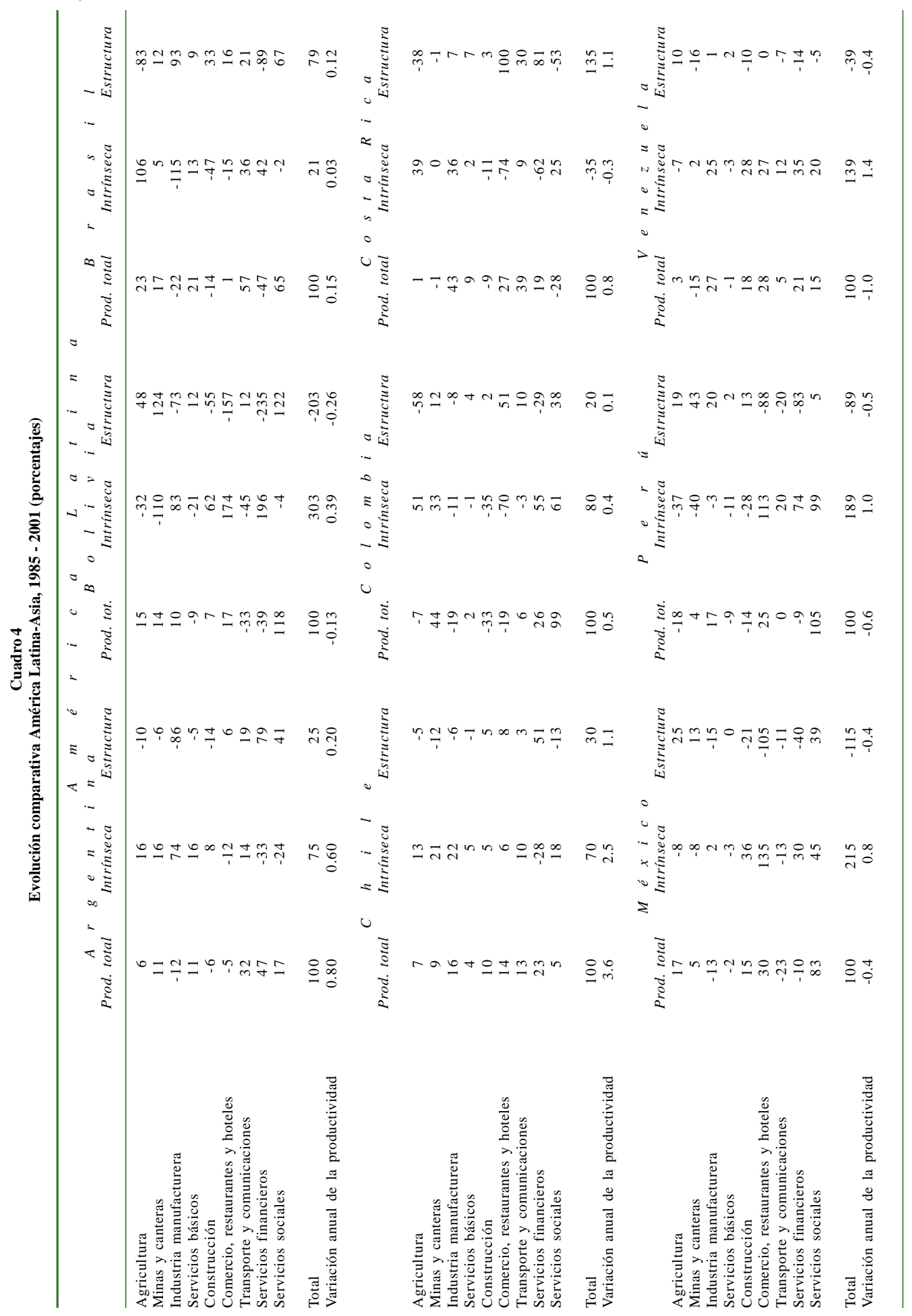

Désarrrollo

Vol. 37, núm. 147, octubre-diciembre / 2006 


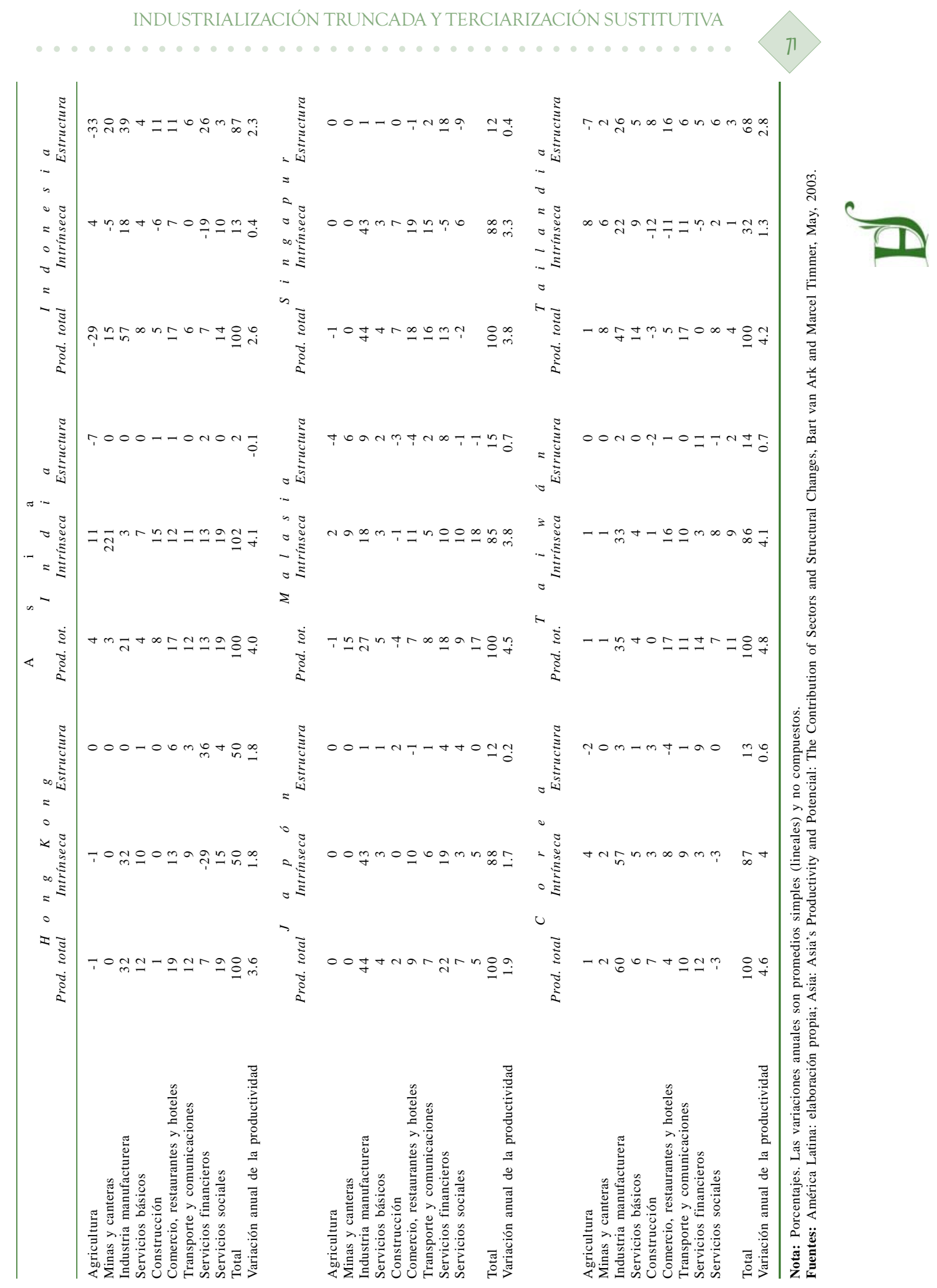

Vol. 37, núm. 147, octubre-diciembre / 2006

Dessarrollo 


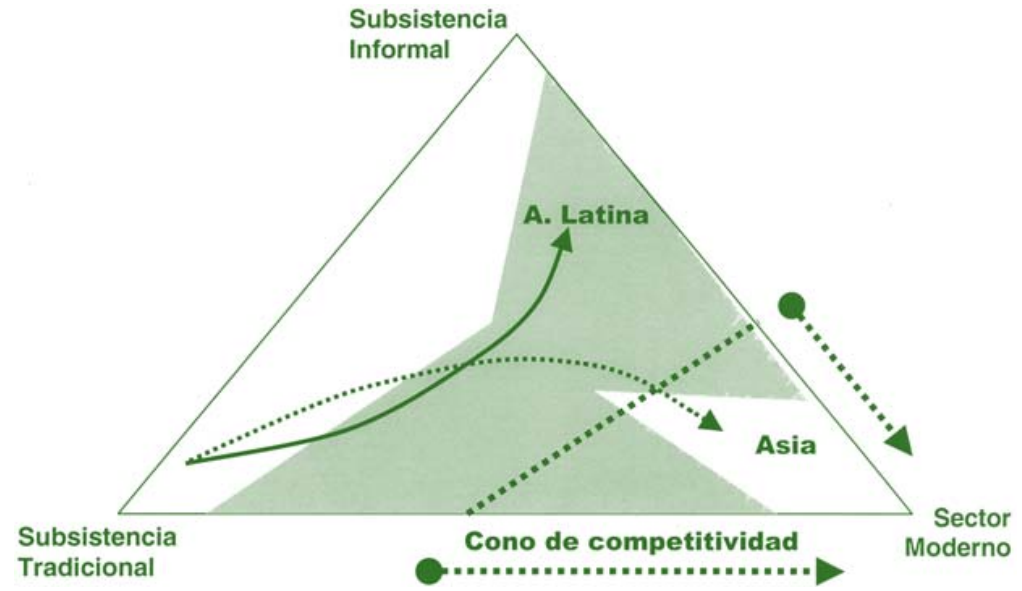

Gráfica 4. Terciarización complementaria y sustitutiva: inequidad ${ }^{a}$ y competitividad.

${ }^{a}$ Las zonas más oscuras del triángulo identifican áreas de mayor desigualdad de ingreso.

no tradicionales de alto crecimiento insertados en complejas cadenas de producción y distribución (CEPAL, 2005).

En cuanto a la manufactura, una investigación reciente (Cimoli et al., 2005) indica que la heterogeneidad de los niveles de productividad media de los trabajadores industriales es mayor en los años noventa en comparación con los setenta. Coexisten algunas pocas empresas mundializadas (sean de capital nacional o internacional) con un amplio grupo de empresas rezagadas. El empleo está aumentando en los sectores industriales más rezagados y el efecto de recomposición estructural de la mano de obra reduce $50 \%$ el crecimiento de la productividad sectorial. La incapacidad de crear empleos en las actividades más cercanas a la frontera productiva limita, a su vez, el efecto de arrastre de esos sectores hacia el sector industrial, y también hasta el resto de la economía. En consecuencia, el aumento de salarios reales se limita a los enclaves competitivos, sin efecto de derrame hacia las otras actividades productivas.

Al interior del sector servicios también se observa una creciente polarización, debido a la generación de empleos en los dos extremos de la escala de salarios (Weller, 2004). O sea, una parte del proceso de terciarización es, como en Asia, complementario al proceso de creciente complejidad y sofisticación del tejido económico, pero esta fracción coexiste con un proceso de descalificación de los empleos de servicio, que volvió a ser dominante en términos de generación de nuevos empleos en la región.

Esa patología dualista puede tener efectos estructurales de largo plazo que perjudican la transición hacia patrones de mayor competitividad. En particular, la falta de perspectivas laborales desanima a una buena parte de las capas más jóvenes para

\section{DeSarrollo}


hacer la necesaria inversión en educación y capital humano. Al mismo tiempo, la dificultad de los recién llegados al mercado de trabajo para encontrar empleos de acuerdo con sus habilidades genera un proceso de depreciación en cascada de los diplomas, a medida que los jóvenes calificados ocupan puestos de menor contenido tecnológico, no logran valorar su inversión en capital humano (Weller, 2006). Esta desvalorización personal genera también pérdidas potenciales en el ámbito macroeconómico, ya que las capacidades productivas disponibles no están usadas eficientemente.

\section{Límites y revisión del marco conceptual}

En el modelo de Lewis, las ganancias de productividad por recomposición de mano de obra tienen que agotarse a medida que la economía transita hacia mayores niveles de desarrollo. En América Latina, sin embargo, la industrialización se quedó truncada y persiste una sobreoferta laboral. ¿Cuáles son las carencias del modelo conceptual inicial?

El esquema inicial se basa en un modelo de economía cerrada, donde los factores limitantes son el acervo de capital disponible en el sector moderno, que depende de la inversión y, por ende, del ahorro interno. Sin embargo, en una pequeña economía de desarrollo abierta, la posibilidad de atraer ahorro externo, sea mediante endeudamiento o inversión extranjera directa, permite acelerar el proceso de transición hacia una economía madura. Las exportaciones suplementan al reducido mercado interno, y actúan como el principal componente de la demanda efectiva en los modelos à la Harrod de multiplicadores de comercio.

La apertura al comercio y a los flujos de capital internacionales aporta, sin embargo, restricciones nuevas que definen la trayectoria sostenible del crecimiento. El éxito de Asia depende muy probablemente de su capacidad de aprovecharse de manera eficiente y sostenible de esas oportunidades. Al contrario, la historia de crisis de balanza de pagos y de devaluaciones masivas que tiene América Latina muestra que las restricciones pueden - y suelen — volverse activas con consecuencias dramáticas. El análisis de estas restricciones han sido analizadas, por ejemplo, en los modelos de brechas para su vertiente financiera (Bacha, 1990), y los modelos de Thirwall (1979), McCombie y Thirwall (1994).

Premisas de un replanteamiento conceptual

En pequeñas economías abiertas, la capacidad de absorción de mano de obra de los sectores modernos está sometida a restricciones externas. Primero, las restricciones de balanza de pagos vienen a interrumpir de manera temprana las fases de auge, dando lugar a ciclos económicos cortos y volátiles. La incertidumbre sistémica desincentiva la inversión de largo plazo; a su vez, el bajo coeficiente de inversión 


\section{HUBERT ESCAITH}

productivo viene a frenar el crecimiento potencial y la absorción de mano de obra excedentaria. Segundo, la apertura a la competencia externa en condición de baja competitividad puede reducir la demanda efectiva para la industria nacional o su tasa de rentabilidad media. A su vez, esa falta de competitividad pone un tope al volumen de empleo y al salario que pueden ofrecer esas empresas. Este fenómeno se agudiza en situación de enfermedad holandesa, típica de las economías exportadoras de bienes primarios. En caso de sobrevaluación real, el único sector moderno que puede incorporar la mano de obra es el de productor de bienes y servicios sin transacciones, que queda protegido de la competencia externa. No obstante, para que sea sustentable, esa absorción adicional de la mano de obra debe venir acompañada de una caída relativa de los salarios reales, para evitar que el alza de la demanda interna desemboque en mayor déficit comercial. La creación de empleos de mala calidad correspondería entonces a un subempleo disfrazado, síntoma de un excedente de trabajo.

Sin embargo, la reducción inducida de salario real no genera un número importante de empleos industriales. Últimamente, dichas condiciones han sido determinadas por la irrupción de China y de la India como productores de bienes y servicios — de bajo costo relativo- a escala mundial. Ello tuvo el mismo impacto que una enfermedad holandesa para los países latinoamericanos que diversificaron sus exportaciones no tradicionales durante los años noventa (Perry y Olarreaga, 2006).

La apertura comercial también ha venido acompañada de mayor movilidad de los factores productivos. En varios países de la región, una respuesta al subempleo ha sido la emigración, en particular hacia Estados Unidos. Las remesas que mandan esos trabajadores expatriados representan un flujo considerable de divisas, que supera en términos regionales al de la inversión extranjera directa. En varios países de Centroamérica y del Caribe esos ingresos superan $10 \%$ del producto interno. Este flujo de divisas, causado inicialmente por el subempleo, aprecia un poco más a las monedas y reduce nuevamente la competitividad externa de las industrias nacionales. ${ }^{7}$

Entonces, las condiciones de equilibrio del mercado de trabajo son parcialmente exógenas, al crear las condiciones de un subempleo estructural. Un modelo revisado para reflejar el nuevo trialismo latinoamericano debería incorporar esos hechos estilizados. Por el lado de la oferta, tres sectores: uno basado en recursos naturales, que cumple la función de sector tradicional al inicio del proceso de transición y se moderniza con el paso del tiempo. Un segundo sector moderno basado, por ejem-

Ecuador llegó a constituir un caso emblemático: la sobrevaloración cambiaria a inicio de 2000 afectó a los productores locales de transables y generó una corriente migratoria de co lombianos y peruanos que venían competir para los reducidos puestos de trabajo disponibles, mientras los nacionales se expatriaban a Europa y a Estados Unidos en búsqueda de trabajo. 
plo, en el modelo de Solow o en una ecuación de crecimiento acumulativa à la Kaldor. Finalmente, un sector moderno de subsistencia (sector informal). En ausencia de restricciones, la dinámica esperada es una migración del primer sector hacia el segundo, incentivada por el diferencial de ingreso.

Lo que imposibilita la transición hacia una industrialización y posindustrialización madura es la existencia de restricciones externas derivadas de las condiciones de equilibrio de largo plazo de la balanza de pagos. Cuando se activan las restricciones externas, surge una insuficiencia de la demanda que desemboca en un desempleo de tipo keynesiano, y un aumento del empleo informal. Los elementos conceptuales para la especificación de esa clase de modelos están analizados en Ros (2000) con un análisis empírico sobre la región en Ros (2005). Cimoli et al. (2006) presentan otro ejemplo reciente de una especificación poskeynesiana aplicada al caso latinoamericano. El Anexo 2 esboza un modelo construido según estas líneas.

\section{Conclusiones}

El trabajo ha presentado una doble desagregación, sectorial y funcional, de la productividad laboral en América Latina, que permite entender de mejor manera su evolución en los últimos 40 años.

En particular, se ha comprobado que los efectos de recomposición estructural de la mano de obra explican la mitad de los cambios de productividad laboral registrados en la región. Contrariamente a lo que planteaba la teoría neoclásica, no hemos presenciado una homogeneización de los mercados de trabajo y los modelos dualistas à la Lewis conservan todavía su poder explicativo.

El ensayo muestra que el caso latinoamericano conforma un cuadro complejo, donde sectores de gran dinamismo en cuanto a su productividad laboral coexistan con actividades de productividad baja y decreciente. La caída que se observa en la productividad laboral media de una serie de sectores de servicios en la región determina un cuadro de terciarización viciosa, sustitutiva de la industrialización en lugar de ser complementaria. La terciarización sustitutiva se explica por la aparición de excedente estructural de mano de obra, síntoma de la incapacidad del sector industrial moderno para crear puestos de trabajo en cantidad suficiente para absorber los aumentos de población económicamente activa resultante de los cambios demográficos, sociales y culturales que ocurrieron en la región. Esta situación redunda en un deterioro relativo de la distribución de los ingresos, y explica por qué no se cumple la profecía de Kuznets en la región en cuanto a la reducción de las ilegalidades a medida que se transita hacia sociedades industrializadas.

En una economía crecientemente globalizada no se puede aislar consideraciones de productividad y de competitividad internacional. La comparación con Asia afianza 
ese diagnóstico, al ofrecer un ejemplo de transición virtuosa, donde la terciarización ha sido complementaria de la industrialización, desembocando en un crecimiento intersectorial equilibrado entre producción de bienes y producción de servicios de creciente valor agregado.

La comparación con Asia es doblemente desfavorable para América Latina. Primero desde una perspectiva estructural interna, porque demuestra la incapacidad histórica de la región para transitar hacia una sociedad industrial homogénea. Segundo, porque diagnostica una falta de competitividad sistémica frente a la competencia asiática.

Efectivamente, la interpretación neoclásica de la evolución de la productividad no permite explicar toda la dinámica observada en la región. Las mediciones de la productividad global de factores realizadas en contabilidad del crecimiento por el tradicional método de la función de producción agregada pueden prestar a diagnósticos erróneos o por lo menos incompletos. La fuerte sensibilidad de la productividad intrínseca al ciclo económico deja pensar que está también determinada por la demanda. Introducir un elemento de demanda en la determinación de la productividad implica, a su vez, introducir elementos de endogeneidad que transforman productividad y crecimiento en un fenómeno cumulativo, al menos hasta cierto punto. Aunque eso es un aspecto fuertemente debatido en la literatura, no cabe duda — por lo menos en el caso de América Latina-, que no se puede explicar la dinámica del crecimiento de largo plazo sin incorporar al modelo elementos de demanda y de sostenibilidad externa.

El sesgo fenomenológico adoptado por el análisis no permite entrar verdaderamente en el debate teórico sobre los determinantes de la productividad ni derivar recomendaciones de políticas. Queda claro, sin embargo, del estudio descriptivo de la situación regional que 1) la movilidad intersectorial de la mano de obra es un factor clave en la determinación de la productividad global, y 2) el subempleo endémico impide movilizar este potencial latente. En la medida que una recomposición positiva del trabajo requiere capacidad y flexibilidad, las políticas de inversión en capital humano y los marcos regulatorios que favorecen la movilidad deberían también reflejarse en mayor productividad global. Sin embargo, esta recomposición deseable no es posible en un ámbito de vulnerabilidad macroeconómica y de pérdida de competencia internacional. Es decir, la solución pasa por la definición de un conjunto articulado de políticas macroeconómicas y sectoriales de largo plazo. 


\section{Bibliografía}

Bacha, Edmar, "A Three-Gap Model of Foreign Transfers and the GDP growth rate in Developing Countries", en Journal of Development Economics, vol. 32, núm 4, 1990, pp. 279-296.

CEPAL, Estudio económico de América Latina y el Caribe, 2005-2006, Santiago de Chile, CEPAL, 2006, $360 \mathrm{pp}$.

_- Panorama 2005: el nuevo patrón de desarrollo de la agricultura en América Latina y el Caribe-Panorama de la Agricultura en América Latina, Santiago de Chile, CEPAL, 2005, 142 pp.

Cimoli, Mario (editor), Heterogeneidad estructural, asimetrías tecnológicas y crecimiento en América Latina, Santiago de Chile, CEPAL/ BID, 2005, 162 pp.

_, Annalisa Primi y Maurizio Pugno, "Un modelo de bajo crecimiento: la informalidad como restricción estructural", en Revista de la CEPAL, núm. 88, Santiago de Chile, abril 2006, pp. 89-107.

De Vries, Gaaitzen J. y André A. Hoffman, Sectoral Database for Latin America Sources and Methods, mimeo., Santiago de Chile, División de Estadística y Proyecciones Económicas de la CEPAL, 2005.

Durlauf, Steven N. y Danny T. Quah, The New Empirics of Economic Growth, Cambridge, NBER, (Working Paper, núm. 6422), 1998, $113 \mathrm{pp}$.

Escaith, Hubert, Can Latin America Fly? Revising its engines of growth, Santiago de Chile, CEPAL, Serie estudios estadísticos y prospectivos, núm. 45, 2006.

Gordon D.M "Kaldor's Macro system: Too Much Accumulation, Too Few Contradictions", en E.J Nell and W. Semmler (editores), Nicholas Kaldor and Mainstream Economics: Confrontation or Convergente?, Nueva York, Macmillan, 1991.

Hernández, Luis Enrique, "La renta petrolera y su impacto en el crecimiento económico de Venezuela", en Problemas del Desarrollo Revista Latinoamericana de Economía, vol. 37, núm. 145, abril-junio 2006, pp. 135-151.

Hofman, André, Economic Growth and Performance in Latin America, Santiago de Chile, CEPAL, Serie reformas económicas, núm. 54, 2000, 46 pp.

Lagos, Ricardo y Camilo Arraigada, Población, pobreza y mercado de trabajo, Lima, оIT, 1998, 505 pp.
Maddison, Angus, "Productivity in an Expanding Economy", Economic Journal, septiembre, 1952 , pp. 584-594.

McCombie John, Maurizio Pugno y Bruno Soro (editores), Productivity Growth and Economic performance: Essays on Verdoorn's Law, Londres, Macmillan, 2002.

Perry, Guillermo y Marcelo Olarreaga, Trade Liberalization, Inequality and Poverty Reduction in Latin America, documento presentado en la Conferencia Anual de Desarrollo Económico del Banco Mundial en San Petersburgo, 2006. 44 pp.

Ranis, Gustav, Is Dualism Worth Revisiting, New Haven, Yale Economic Growth Center, Working Paper Series, núm. 870, 2003.

Ranis, Gustav, Labor Surplus Economies, New Haven, Yale Economic Growth Center, Working Paper Series, núm. 900, 2004.

Ros, Jaime, El desempleo en América Latina desde 1990, México, CEPAL, Serie estudios y Perspectivas, núm. 29, 2005, 34 pp.

, Development Theory and the Economics of Growth, Ann Arbor, University of Michigan Press, 2000, 429 pp.

Sánchez Almanza, Adolfo, "Crecimiento económico, desigualdad y pobreza: una reflexión a partir de Kuznets", en Problemas del Desarrollo, Revista Latinoamericana de Economía, vol. 37, núm. 145, abril-junio 2006, pp. 11-31.

Scott, Maurice Fitzgerald, A New View of Economic growth, Oxford, Clarendon Press, 1989.

Solow, Robert. M., "A Contribution to the Theory of Economic Growth" en Quarterly Journal of Economics, vol. 70, núm.1, febrero 1956, pp. 65-95.

Weller, Jürgen (editor), Los jóvenes y el empleo en América Latina: desafios y perspectivas ante el nuevo escenario laboral, Bogotá, Ediciones Mayol-CEPAL, 2006. 328 pp.

Weller, Jürgen, "Problemas de empleo, tendencias subregionales y políticas para mejorar la inserción laboral", Santiago de Chile, CEPAL, Serie Macroeconomía del Desarrollo, núm. 40, 2005, $50 \mathrm{pp}$.

-, "El empleo terciario en América Latina: entre la modernidad y la sobrevivencia", en Revista de la CEPAL, núm. 84, Santiago de Chile, diciembre 2004, pp. 159-176. 


\section{Anexo I. Apéndice estadístico}

La principal limitación estadística reside en la disponibilidad de información sobre la población empleada por sector de actividad. Se utilizaron los datos de De Vries y Hofman (2005), basados en los censos de población y encuestas de hogares, y ajustados por nivel de desempleo en Argentina, Bolivia, Brasil, Chile, Colombia, Costa Rica, México, Perú, y Venezuela para el periodo 1950-2003. Debido a algunas diferencias de cobertura al inicio de la serie, se restringe el lapso de análisis a 1960-2003. En el caso particular de la agricultura, no se podía contar con una cobertura satisfactoria de las encuestas de hogares que excluían, por lo general, al área rural. Para el periodo 1990-2003, estos últimos datos fueron recalibrados por el autor, al usar estimaciones de población activa agrícola de la CEPAL.

\section{Actividad económica}

El valor agregado desglosado según los nueve sectores de actividades definidos por el sistema de cuentas nacionales se basó en los datos regionales en dólares calculados por la CEPAL.

Como es conocido, la ponderación relativa de los sectores en el PIB total depende del año base de las cuentas nacionales. Al cambiar dicho año se modifican los precios y pesos relativos entre los sectores, lo cual introduce un elemento de distorsión en el análisis. La estructura de precios relativos existente al momento de la toma de decisiones - como parte de los incentivos que motivaron la reasignación de recursos- es importante mantenerla en el análisis histórico. Por lo tanto, se buscó mantener un equilibrio entre $a$ ) normalizar los niveles generales de producto interno en torno de un mismo año base, para realizar una comparación histórica, y b) preservar la estructura sectorial de precios relativos existente en cada periodo. La solución heurística fue de realizar un empalme parcial de las series de cuentas nacionales, trasladando todos los datos sectoriales a precios de 2000, ajustando cada serie a precios de 1970 y 1980 por un factor constante usando el PIB total como pivote.

Los datos anuales de valor agregado y de población activa sectorial fueron suavizados mediante un promedio móvil de tres años centrado en el año de referencia, para filtrar los impulsos de corto plazo. Ese proceso de suavización filtra las fluctuaciones de más alta frecuencia, pero preserva los movimientos cíclicos.

\section{Anexo II. Modelo revisado}

Se trata aquí de ofrecer algunas pistas para la especificación de un modelo ecléctico que podría servir para orientar una investigación empírica. Con base en los hechos estilizados identificados, podemos definir tres sectores.

\section{DeSarrollo}


1) El sector intensivo en recursos naturales (v.g., agrícola), con una función de producción a factores complementarios:

$$
\mathrm{Y}_{\mathrm{a}}=\operatorname{Min}\left[\mathrm{e}^{\text {qa(t) }}\left(\text { Tierra) } ; \mathrm{w}_{\mathrm{s}} \mathrm{L}_{\mathrm{a}}\right]\right.
$$

$\Psi_{a}(t)$ : función de la brecha tecnológica con los países industrializados, ponderada por la capacidad para incorporar esa tecnología. A mayor brecha, mayor velocidad de difusión, siguiendo un proceso de catching-up à la Abramovitz (1986). Su difusión es exógena y la transferencia de tecnología no se enfrenta a dificultades particulares de adopción.

$\mathrm{L}_{\mathrm{a}}$ : mano de obra disponible en el sector rural, donde la única fuente de actividad es la agricultura

$\mathrm{w}_{\mathrm{s}}=$ salario de subsistencia.

$\mathrm{w}_{\mathrm{a}}=\mathrm{Y}_{\mathrm{a}} / \mathrm{L}_{\mathrm{a}}>=\mathrm{w}_{\mathrm{s}}$

Se supone que por razones culturales, la migración rural es irreversible y no hay migración desde las ciudades hacia el campo.

2) El sector urbano moderno usa una tecnología tipo Cobb-Douglas:

$\mathrm{Y}_{\mathrm{m}}=\mathrm{Ae}_{\mathrm{m}}^{\underset{\mathrm{f}}{(t)}} \mathrm{K}^{\alpha}\left(\mathrm{L}_{\mathrm{m}}\right)^{1-\alpha}$

$\mathrm{L}_{\mathrm{m}}$ : empleo formal en el sector moderno

$\mathrm{w}_{\mathrm{m}}>\mathrm{w}_{\mathrm{s}}$

$\Psi_{\mathrm{m}}(\mathrm{t})$ : potencial de catching-up debido a la brecha del progreso tecnológico relativo en el sector industrial. Su difusión es exógena, pero la capacidad de incorporación de tecnología cada vez más compleja es más limitada que en el sector agrícola. Por lo tanto, $\mathrm{d} \psi_{\mathrm{m}} / \mathrm{dt}$ puede tener valores positivos (cierre de brecha) o negativos (retraso tecnológico relativo).

3) El sector informal urbano tiene una función de producción con retornos constantes en relación con el trabajo:

$$
\begin{aligned}
& \mathrm{Y}_{\mathrm{i}}=\mathrm{w}_{\mathrm{s}} \cdot \mathrm{L}_{\mathrm{i}} \\
& \mathrm{L}_{\mathrm{i}}=\text { empleo informal (residual) } \\
& \mathrm{L}_{\mathrm{i}}=\mathrm{L}-\mathrm{L}_{\mathrm{a}}+\mathrm{L}_{\mathrm{m}} \\
& \mathrm{Y}=\mathrm{Y}_{\mathrm{a}}+\mathrm{Y}_{\mathrm{m}}+\mathrm{Y}_{\mathrm{i}}
\end{aligned}
$$


Existen restricciones de crecimiento que afectan la dinámica del sistema. Fijamos el máximo de crecimiento alcanzable $\left(\mathrm{y}^{*}=\mathrm{Max} \mathrm{dy} / \mathrm{dt}\right)$ sin desequilibrio externo por la restricción externa, ampliando el modelo de Thirlwall (1979) por el concepto de brecha tecnológica:

$$
\begin{aligned}
& \mathrm{x}=\alpha_{1} q+\varepsilon \ddot{y} \\
& \mathrm{~m}=\alpha_{2} q+\pi y
\end{aligned}
$$

Las variables son expresadas en tasa de variación: (x) y (m) son las exportaciones y las importaciones; (y) es el producto de la economía en desarrollo; (q) es el tipo de cambio real; ( $\ddot{\mathrm{y}}$ ) es el producto del resto del mundo. Los parámetros $(\alpha 1)$ y $(02)$ son las elasticidades precio de importación y exportación, $(\varepsilon)$ y $(\pi)$ las elasticidades-producto.

Las elasticidades-producto $(\varepsilon)$ y $(\pi)$ dependen de la brecha tecnológica (Escaith, 2006).

$$
\begin{aligned}
& \varepsilon=\phi\left(\psi^{1}\right) \\
& \pi=\theta(\psi)
\end{aligned}
$$

Para que la dinámica sea sostenible en el largo plazo, la balanza comercial debe permanecer en equilibrio $(x=m)$. La trayectoria de crecimiento de equilibrio para el PIB potencial $\left(\mathrm{y}^{*}\right)$ está entonces determinada por el crecimiento de la demanda externa (ÿ) y por las elasticidad-producto de la oferta y demanda externas.

$\ddot{y}$ es independiente de $\mathrm{y}^{*}$, entonces, la convergencia del ingreso por habitante con los países desarrollados (y* > ÿ) implica:

$$
\alpha_{1} q+\varepsilon\left(\psi^{1}\right) \ddot{y}>\alpha_{2} q+\pi(\psi) y
$$

En caso contrario, por ejemplo, cuando el sector productor de transables no es competitivo internacionalmente debido a factores técnicos ( $\psi$ ), cambiarios (q) o sistémicos $\left(\alpha_{1} \alpha_{2}\right)$, su tasa de crecimiento está limitada. En esta situación, el excedente de mano de obra sólo puede emplearse en el sector informal de baja productividad y la tasa de crecimiento de la economía (y*) se reduce.

Nótese que en este modelo ecléctico, la brecha tecnológica actúa a la vez como un acelerador de catching-up (efecto oferta) y un reductor del multiplicador de comercio (efecto demanda).

\section{Desarrollo}

